\title{
Coastal
}

\section{Validation and intercomparisons of wave measurements and models during the EuroROSE experiments}

\author{
L.R. Wyatt ${ }^{\mathrm{a}, *}$, J.J. Green ${ }^{\mathrm{a}}$, K.-W. Gurgel ${ }^{\mathrm{b}}$, J.C. Nieto Borge ${ }^{\mathrm{c}}$, K. Reichert ${ }^{\mathrm{d}}$,

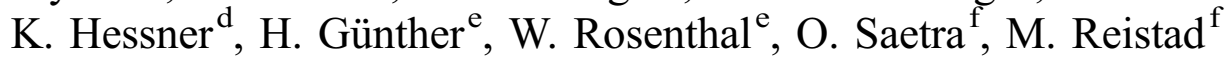 \\ ${ }^{a}$ SCEOS, Department Applied Mathematics, School of Mathematics and Statistics, University of Sheffield, Hicks Building, \\ Hounsfield Road, Sheffield S3 7RH, UK \\ ${ }^{\mathrm{b}}$ Universität Hamburg, Institut für Meereskunde, Troplowitzstrasse 7, D-22529 Hamburg, Germany \\ ${ }^{\mathrm{c}}$ Puertos del Estado, Clima Maritimo, C/Antonio Lopez 81, ES-28026 Madrid, Spain \\ ${ }^{\mathrm{d} O c e a n W a v e S} \mathrm{GmbH}$, Munstermannskamp 1, D-21335, Lüneburg, Germany \\ ${ }^{\mathrm{e}}$ GKSS Forschungszentrum Geesthacht, Institute for Coastal Research, Max Planck Strasse, D-21502 Geesthacht, Germany \\ ${ }^{\mathrm{f}}$ Norwegian Meteorological Institute R\&D, Niels Henrik Abels vei 40, POB 43, Blindern, 0313 Oslo, Norway
}

Received 16 January 2002; received in revised form 17 October 2002; accepted 8 November 2002

\begin{abstract}
The objective of the EuroROSE (European Radar Ocean Sensing) project was to combine area covering ground-based remote-sensed wave and current data with high-resolution numerical forecast models to provide nowcasts and forecasts for coastal marine operators. Two experiments to test and to demonstrate the system took place: one on the coast of Norway, north of Bergen in March 2000 and the second on the north coast of Spain at Gijon in October-November 2000. Qualitative and quantitative intercomparisons of the wave measurements and wave model products from these experiments are presented. These include measurements using the Wellen Radar (WERA) high-frequency (HF) radar, the WaMoS (Wave Monitoring System) Xband radar, a directional Waverider and output from the WAM wave model. Comparisons are made of the full directional spectra and of various derived parameters. This is the first-ever intercomparison between HF and X-band radar wave measurements and between either of these and WAM. It has provided a data set covering a much wider range of storm and swell conditions than had been available previously for radar wave-measurement validation purposes and has clarified a number of limitations of the radars as well as providing a lot of very useful radar wave data for future model-validation applications. The intercomparison has led to improvements in the data quality control procedures of both WaMoS and WERA. The two radar sytems measured significant wave height with mean biases of $3 \%$ and $6 \%$, respectively, and mean direction differences of less than $2^{\circ}$ in both cases. Limitations in the WAM model implementation are also discussed.
\end{abstract}

(C) 2002 Elsevier Science B.V. All rights reserved.

Keywords: Wave measurement; WAM wave model; HF radar; X-band radar; Waverider; EuroROSE

* Corresponding author. Tel.: +44-114-23794; fax: +44-114-23809.

E-mail addresses: 1.wyatt@sheffield.ac.uk (L.R.Wyatt),j.j.green@sheffield.ac.uk (J.J. Green), gurgel@ifm.uni-hamburg.de (K.-W. Gurgel), joscar@puertos.es (J.C. Nieto Borge), reichert@oceanwaves.de (K. Reichert), hessner@oceanwaves.de (K. Hessner), guenther@gkss.de (H. Günther), rosenthal@gkss.de (W. Rosenthal), was@ecmwf.int (O. Saetra), magnar.reistad@met.no (M. Reistad). 


\section{Introduction}

\subsection{EuroROSE}

An important goal of the Global Ocean-Observing System (GOOS) project is to develop operational tools for use by those who are responsible for coastal marine operations and constructions as well as for protection of the marine environment, e.g., Vessel Traffic Services (VTS), harbour, coast and waterways managers. These applications are in the process of rapid development due to a general increase in traffic density and to the impact of new environmental protection legislation both local and international. In the context of VTS operations, the governing met-ocean conditions (winds, waves, waterlevel and currents) affect the safety and maneuverability of ships. The requirement for this met-ocean information is not limited to the actual location of interest, e.g., the immediate vicinity of a harbour, but extends to a fairly extensive area around this focal point. This is due to the strong spatial and temporal variability of coastal seas.

The required information is typically provided by point measurements, using buoys, e.g., at one or two locations. Model forecast information is provided, but normally on rather coarse grids (typical spacing might be $10-50 \mathrm{~km}$ ) and slow update rates (perhaps $6-12$ h). A finer spatial and temporal resolution is needed for harbours with a shallow or narrow approach channel. For example, a crude oil tanker needs environmental parameters on space and time scales of a few hundred meters and 1 or $2 \mathrm{~h}$, respectively, to decide on its course into a harbour. The EuroROSE project is aimed to take advantage of fine-resolution numerical models together with ground-based radar sensors to provide the needed spatial and temporal resolution. Some of the parameters measured by the radars were assimilated into wave and current models providing now and forecast fields. The measurements and predictions were available to VTS operators in real time, via a purpose-designed computer interface, during two experiments at two different locations: Fedje in Norway and Gijon in Spain.

This paper concentrates on the wave measurements and model; the current measurements and model are discussed elsewhere (Breivik and Saetra, 2001; Essen et al., 2002). Further information on the experiments can be found on the EuroROSE web site (http://
ifmaxp1.ifm.uni-hamburg.de/EuroROSE/index.html) and the data are also available from that site.

\subsection{Description of instruments, model and assim- ilation procedures}

The radar systems being evaluated in the EuroROSE project are the Wellen Radar (WERA) high-frequency (HF) radar (Gurgel et al., 1999) and the WaMoS Xband radar (Borge et al., 1999a,b). These are compared with a directional Waverider buoy at Fedje and a nondirectional Waverider at Gijon. In addition, the WAM cycle 4 wave model (WAMDI Group, 1988; Komen et al., 1994) was used with assimilation of WERA significant wave-height measurements. The Fedje experiment provided the first-ever opportunity to both intercompare the two very different radar systems and to compare them with WAM.

The directional wave buoy data are available in parametric form. These contain energy density, $E(f)$; mean wave direction, $\theta_{\mathrm{m}}(f)$; directional spread, $\sigma_{\mathrm{m}}(f)$; skewness and kurtosis; and the four Fourier coefficients: $a_{1}(f), b_{1}(f), a_{2}(f)$ and $b_{2}(f)$ at frequencies from 0.025 to $0.58 \mathrm{~Hz}$ in increments of 0.005 to $0.1 \mathrm{~Hz}$ and $0.01 \mathrm{~Hz}$ thereon. For comparisons of the full directional spectrum, the maximum entropy method (Lygre and Krogstad, 1986) has been used to estimate the buoy spectrum. This requires the four Fourier coefficients. The nondirectional buoys provide only energy density, $E(f)$.

WERA was developed during the EU-funded SCAWVEX (Surface Current And Wave Variability Experiments) project (Gurgel et al., 1999) and is an FMCW (Frequency Modulated Continuous Wave) HF radar providing surface-current measurements to over $40 \mathrm{~km}$ and wave measurements to $20 \mathrm{~km}$ with a spatial resolution of about $1 \mathrm{~km}^{2}$. The spectrum of the backscattered signal is inverted to provide measurements of the ocean wave spectrum. This inversion procedure provides directional wave spectra on a nonuniform grid of wave numbers (Wyatt, 2000). These are converted to directional frequency spectra, $S(f, \theta)$, using the finite-depth dispersion relationship for wave number to frequency conversion in the transformation, and averaged into frequency-direction bins with 60 frequencies (from 0.03 to $0.5 \mathrm{~Hz}$ in increments of 0.005 to $0.15 \mathrm{~Hz}$ and $0.01 \mathrm{~Hz}$ thereon) and 24 directions $\left(15^{\circ}\right.$ increments) and then integrated 
(in direction) to provide the data in the same parametric form measured by the buoy. No external calibration is required in this procedure. At this stage, no attempt has been made to make use of the radar current measurements to account for any associated Doppler shifting of the higher frequency waves.

The WaMoS radar has been available commercially for wave measurements for some time. It can image the sea surface at ranges up to $2 \mathrm{~km}$ from the radar site. It repeatedly scans the surface and obtains the directional spectrum by Fourier transforms in space and time. Amplitude is obtained by calibration with a buoy. For the comparisons presented here, the mean frequency direction spectrum, which is provided in matrix form, $S(f, \theta)$, with 64 frequencies (from 0 to $0.315 \mathrm{~Hz}$ in $0.005-\mathrm{Hz}$ steps) and 90 directions $\left(4^{\circ}\right.$ increments), has been used. These have been integrated (in direction) to provide the data in the same parametric form measured by the buoy. More details on the WaMoS installations and analysis procedures used during the EuroROSE experiments can be found in Hessner et al. (2000a,b).

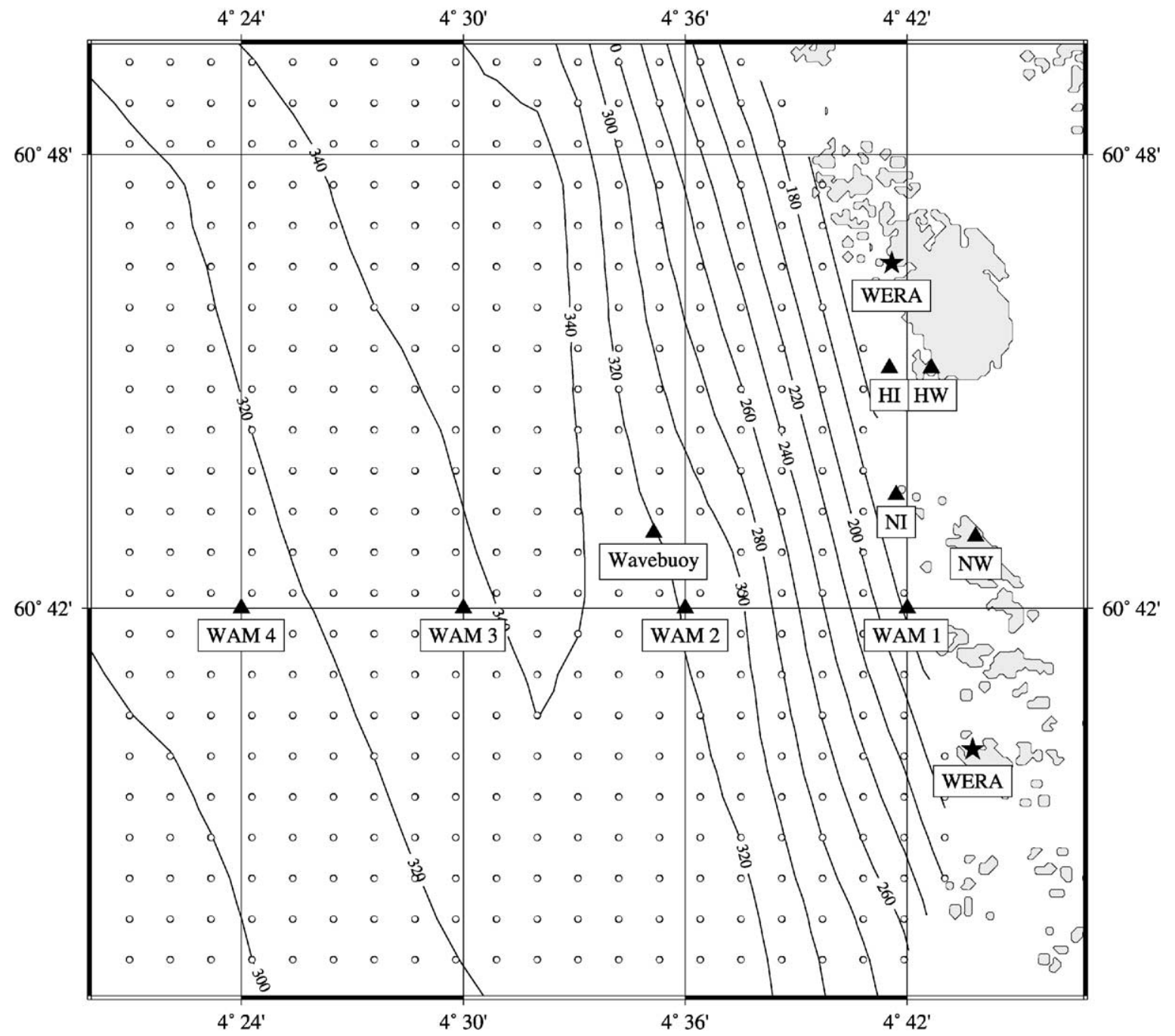

Fig. 1. Map of the Fedje site on the west coast of Norway showing WERA radar sites (WERA) and all potential measurement positions (O); wavebuoy location; WAM locations where full directional spectra were stored (1-4); WaMoS radar sites (NW, HW) and corresponding image locations (NI, HI). Bottom depths are contoured at 20-m intervals. 
A three-step nested version of WAM was implemented for these experiments. At Fedje, this comprised a $45-\mathrm{km}$ resolution North Atlantic grid, an 8$\mathrm{km}$ North Sea grid and a 1-km local grid, the latter covering a little bit more than the WERA grid. The WAM data is provided as the mean frequency direction spectrum and is also in matrix form, with 25 frequencies (from 0.042 to $0.4137 \mathrm{~Hz}$ in $10 \%$ steps) and 24 directions ( $15^{\circ}$ increments). These have been integrated (in direction) to provide the data in the same parametric form measured by the buoy. These data are from the analysis time (every hour) and include the assimilation of HF radar significant wave height at times $-0040,-0020$ and $0000 \mathrm{~h}$ relative to the analysis time. The assimilation method used is discussed in Breivik and Reistad (1994). A limited set of parameters was stored for all other locations. The analysis and 6-h forecast were available at the VTS centre less than 45 min after the observation time.

\subsection{Specific goals of this paper}

This paper discusses the wave measurements and model and their intercomparison and validation. The aim is to provide a comprehensive state-of-the-art report on the quality of wave measurements from the two ground-based radar systems, WaMoS and WERA, used. Previous intercomparison work (e.g., Wyatt et al., 1999) has shown how important it is not to rely on significant wave height and mean direction as the only parameters with which to judge a measurement of the directional spectrum. Detailed evaluations of directional spectra and comparisons over narrow frequency bands are needed to understand discrepancies in the parameter comparisons and the analysis presented here takes that approach. The next section presents an overview of both experiments. This is followed in Section 3 with first a qualitative and then a quantitative description of the comparisons. In

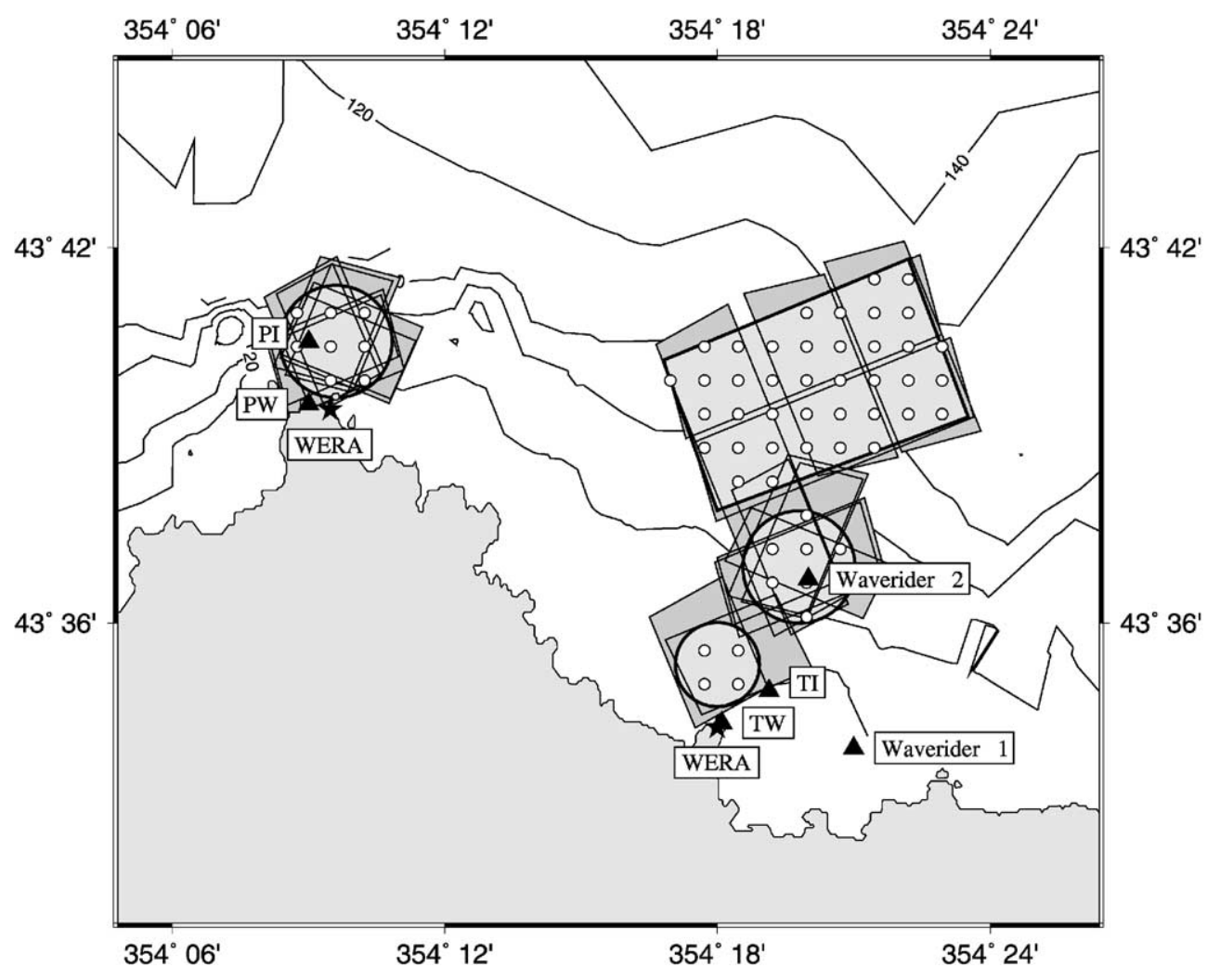

Fig. 2. Map of the Gijon site on the north coast of Spain showing WERA radar sites (WERA) and all potential measurement positions (O) within the InSAR imaging regions (shaded regions); Waverider locations; WaMoS radar sites (PW, TW) and corresponding image locations (PI, TI). Bottom depths are contoured at 20-m intervals. 

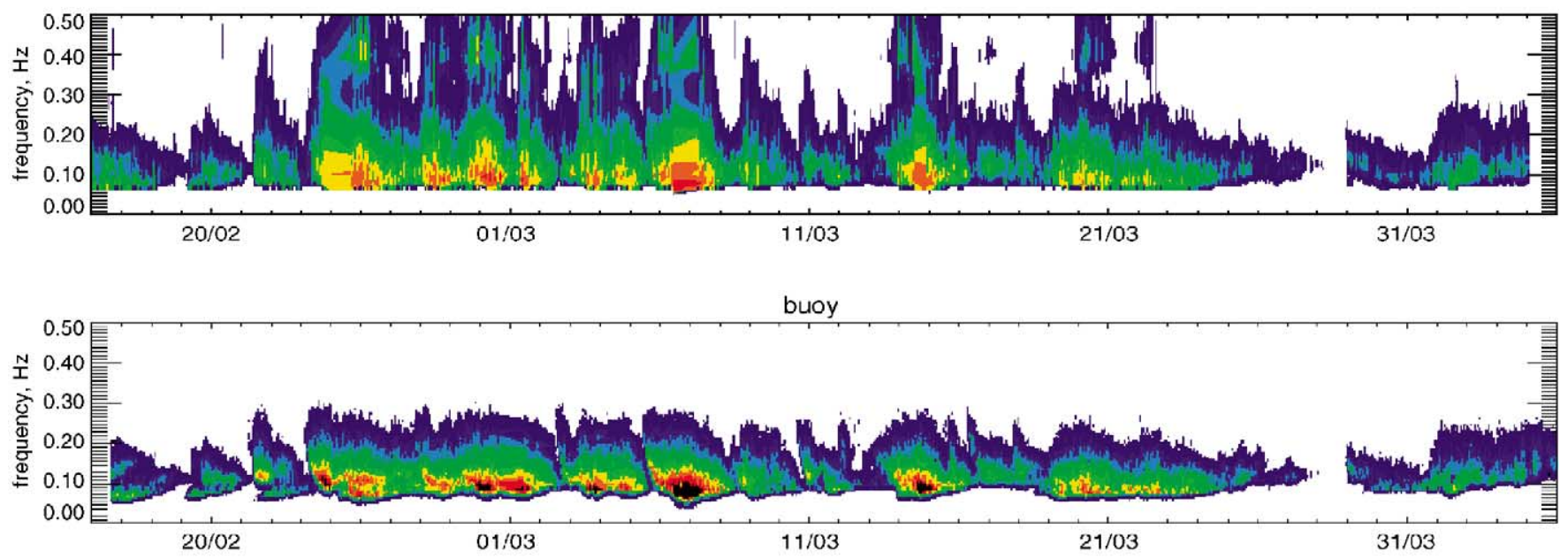

WaMos

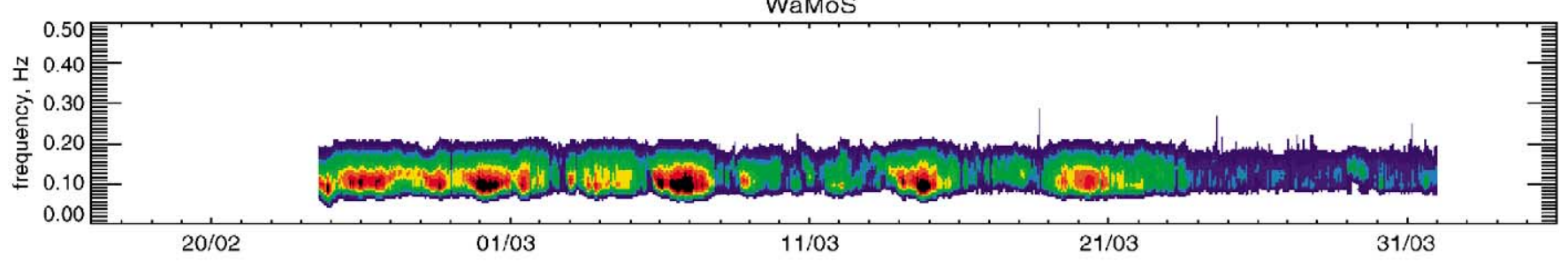

WAM

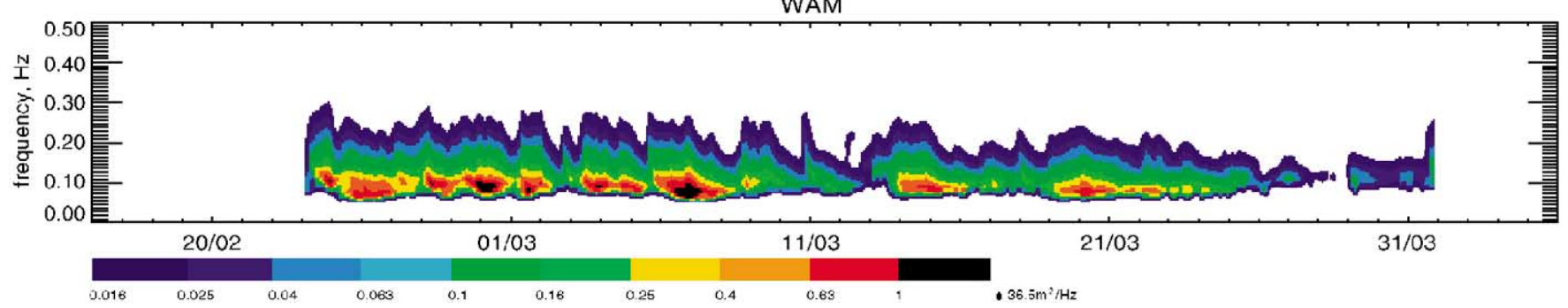

Fig. 3. Frequency spectra during the Fedje experiment. From top to bottom: WERA, buoy, WaMoS and WAM. The colour scaling is logarithmic as shown and normalised to the maximum value measured by WERA during the whole experiment. 
WERA
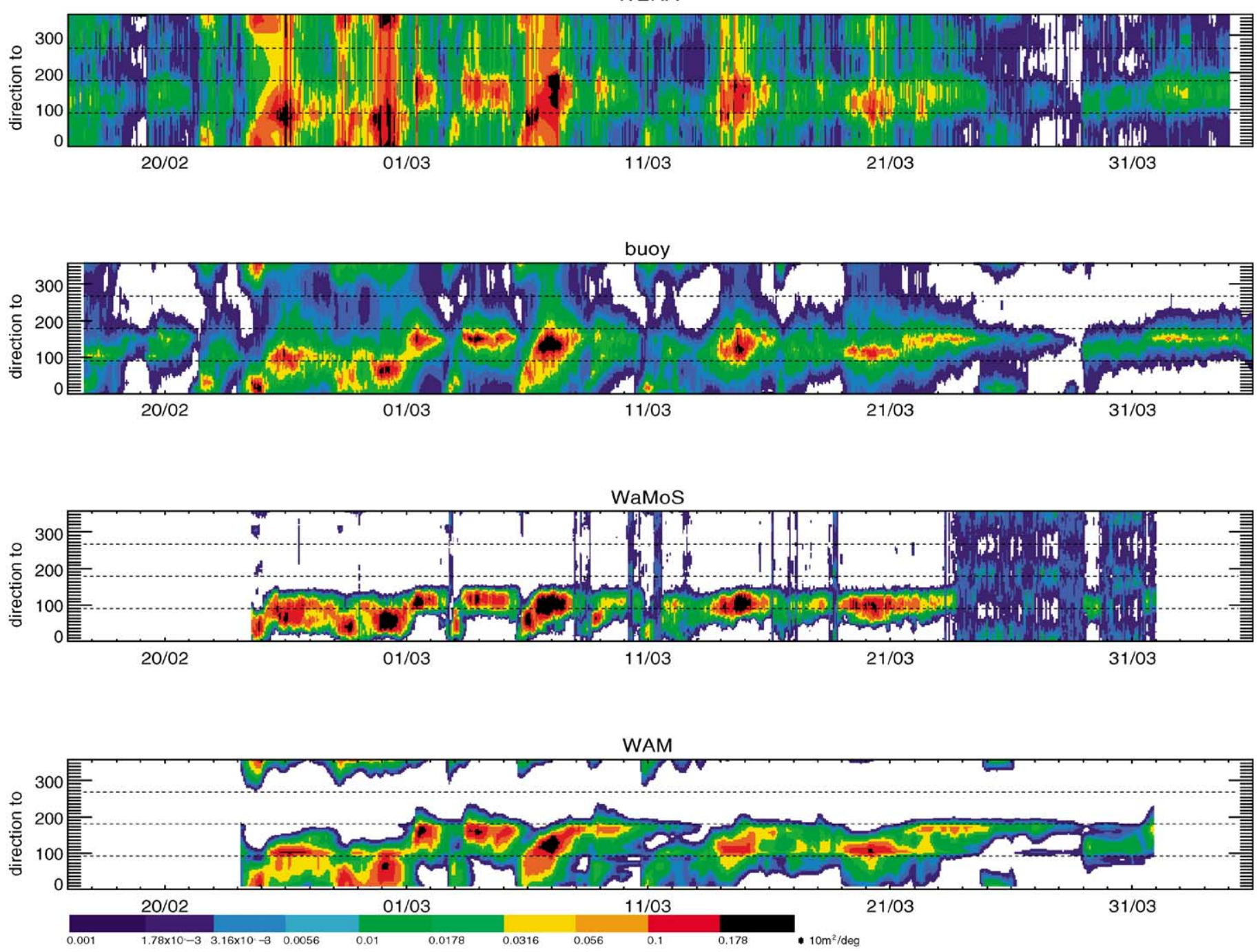

Fig. 4. Direction spectra during the Fedje experiment. From top to bottom: WERA, buoy, WaMoS and WAM. The colour scaling is logarithmic and is normalised as shown. 

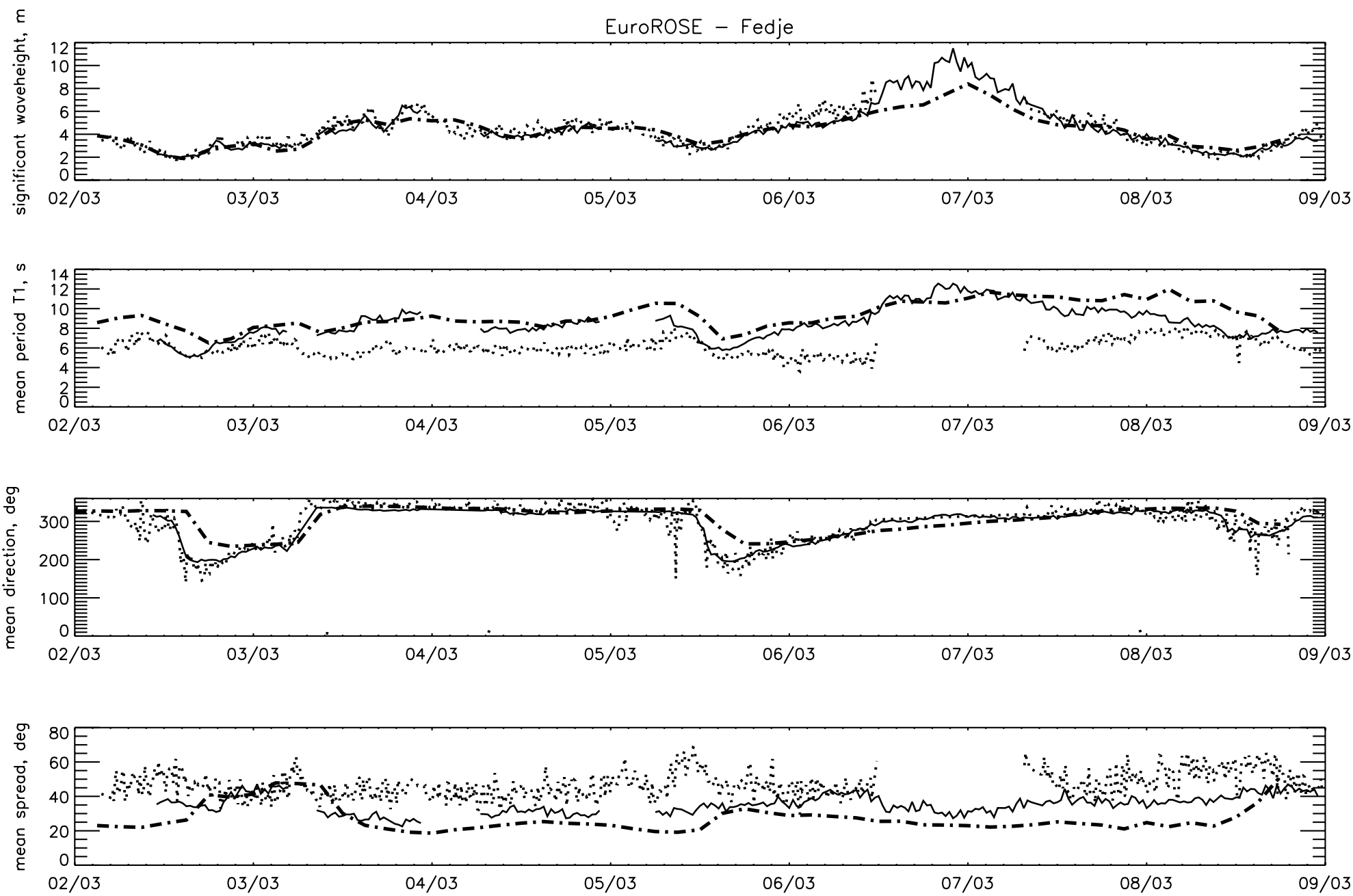

Fig. 5. Significant wave height, mean period, direction and spread comparisons at the buoy position at Fedje. Solid line is the buoy measurement, dash-dot is the WAM and dotted is the WERA. 
Section 4, the performance of each instrument and of the model and, in particular, the assimilation impact, are discussed separately, followed by a discussion of the way in which their complementarity was exploited in EuroROSE and, lastly, by some recommendations for future work.

\section{Overview of experiments}

Figs. 1 and 2 show the locations of the two experiments and the measurement sites northwest of Bergen in Norway and at the port of Gijon in Northern Spain. The Fedje map shows the location of the two WaMoS radars on the islands of Hellisøy (HW) and Nordøy (NW). The region of the sea surface that are imaged from these locations are indicated with $\mathrm{HI}$ and NI, respectively. The Nordøy imaging site is further away from the radar and is in a region of small rocky outcrops. The Hellisøy site is sheltered from the north. The two HF radar (WERA) sites are shown. One of these (the southern one) was on an isolated island that could only be reached by helicopter or small boat. The other was located near the VTS centre on the island of Fedje, and both radars were controlled from the centre. The WERA measurement grid, with a spacing of $1 \mathrm{~km}^{2}$, is shown on the map. Wave measurements are not always available at all locations. The WAM wave model used a similar grid, and some parameters were stored every hour for each grid location. Directional spectra were only stored every third hour at the locations indicated by WAM1-4 on the map. These are used for more detailed evaluations of the measurements and the model. A Datawell directional Waverider was deployed as shown.

In Spain, the WaMoS and WERA radars were located at neighbouring sites at Torres and Peñas near the port of Gijon. These are indicated with the letters $\mathrm{T}$ and $\mathrm{P}$, respectively, on Fig. 2. The WaMoS imaging areas from the two locations are shown with TI and PI, respectively. WERA wave measurements were again obtained on a $1-\mathrm{km}^{2}$ grid over an area between the two sites; however, the only points in the grid shown in Fig. 2 are those from which the directional spectra were stored for detailed evaluation by comparison with the buoy, WaMoS and, in particular, for comparisons with an experimental interferometric SAR flown over the region in an aircraft in November 9. The results of this special measurement period will be published separately. Unfortunately, the directional wave buoy that should have provided 'sea-truth' data for the radar systems failed before the start of the experiment and only nondirectional data is available.

At Fedje, wind speeds were generally high with speeds over $10 \mathrm{~m} / \mathrm{s}$ on many occasions, and directions are rather variable associated with the passage of a series of lows and frontal systems across the region. Wind speeds were significantly lower and directions

Table 1

Fedje WERA, WAM and buoy parameter comparisons

\begin{tabular}{|c|c|c|c|c|c|c|c|}
\hline \multirow[t]{2}{*}{ Wave parameter } & \multirow[t]{2}{*}{ Frequency range } & \multicolumn{2}{|c|}{ WERA/buoy } & \multicolumn{2}{|c|}{ WERA/WAM } & \multicolumn{2}{|c|}{ WAM/buoy } \\
\hline & & $\mathrm{cc}$ & $m(\mathrm{sd})$ & $\mathrm{cc}$ & $m(\mathrm{sd})$ & $\mathrm{cc}$ & $m(\mathrm{sd})$ \\
\hline \multirow[t]{5}{*}{ Hs } & Full range & 0.96 & $6 \%(14.7 \%)$ & 0.93 & $-2.3 \%(17.2 \%)$ & 0.94 & $8.2 \%(15.8 \%)$ \\
\hline & $\begin{array}{l}\text { Peak from 1D } \\
\text { frequency spectrum }\end{array}$ & 0.85 & $-27.4 \%(17.9 \%)$ & 0.85 & $-39.7 \%(13.1 \%)$ & 0.89 & $16.1 \%(25.9 \%)$ \\
\hline & $0.05-0.1$ & 0.93 & $-6.2 \%(21.4 \%)$ & 0.91 & $-23.8 \%(22.1 \%)$ & 0.92 & $25.8 \%(42.7 \%)$ \\
\hline & $0.1-0.2$ & 0.92 & $7.1 \%(17.1 \%)$ & 0.87 & $13.7 \%(25.1 \%)$ & 0.93 & $-4.2 \%(17.8 \%)$ \\
\hline & $0.2-0.3$ & 0.85 & $37.4 \%(33.9 \%)$ & 0.75 & $79.3 \%(62.8 \%)$ & 0.81 & $-15.8 \%(25.7 \%)$ \\
\hline $\begin{array}{l}\text { First moment } \\
\text { Period }\end{array}$ & Full range & 0.46 & $-13.1 \%(14.8 \%)$ & 0.31 & $-25.8 \%(13 \%)$ & 0.7 & $14.6 \%(19.2 \%)$ \\
\hline \multirow[t]{5}{*}{ Direction } & Full range & 0.81 & $1.9^{\circ}\left(27.6^{\circ}\right)$ & 0.72 & $-3.6^{\circ}\left(31^{\circ}\right)$ & 0.76 & $6.5^{\circ}\left(26.1^{\circ}\right)$ \\
\hline & $\begin{array}{l}\text { Peak from } 1 \mathrm{D} \\
\text { frequency spectrum }\end{array}$ & 0.38 & $5.3^{\circ}\left(55.5^{\circ}\right)$ & 0.49 & $-1.2^{\circ}\left(47.7^{\circ}\right)$ & 0.53 & $8^{\circ}\left(35.9^{\circ}\right)$ \\
\hline & $0.05-0.1$ & 0.29 & $7.7^{\circ}\left(60.2^{\circ}\right)$ & 0.32 & $6.7^{\circ}\left(55.6^{\circ}\right)$ & 0.77 & $1.8^{\circ}\left(19.4^{\circ}\right)$ \\
\hline & $0.1-0.2$ & 0.87 & $4.3^{\circ}\left(20.8^{\circ}\right)$ & 0.76 & $4.1^{\circ}\left(27.4^{\circ}\right)$ & 0.83 & $-0.9^{\circ}\left(22.3^{\circ}\right)$ \\
\hline & $0.2-0.3$ & 0.85 & $6.9^{\circ}\left(25.9^{\circ}\right)$ & 0.74 & $5.7^{\circ}\left(34.4^{\circ}\right)$ & 0.74 & $1.7^{\circ}\left(34.1^{\circ}\right)$ \\
\hline
\end{tabular}

cc-Correlation coefficient; $m$-Mean; sd-Standard deviation. 
EuroROSE - Fedje at position Hellisoy
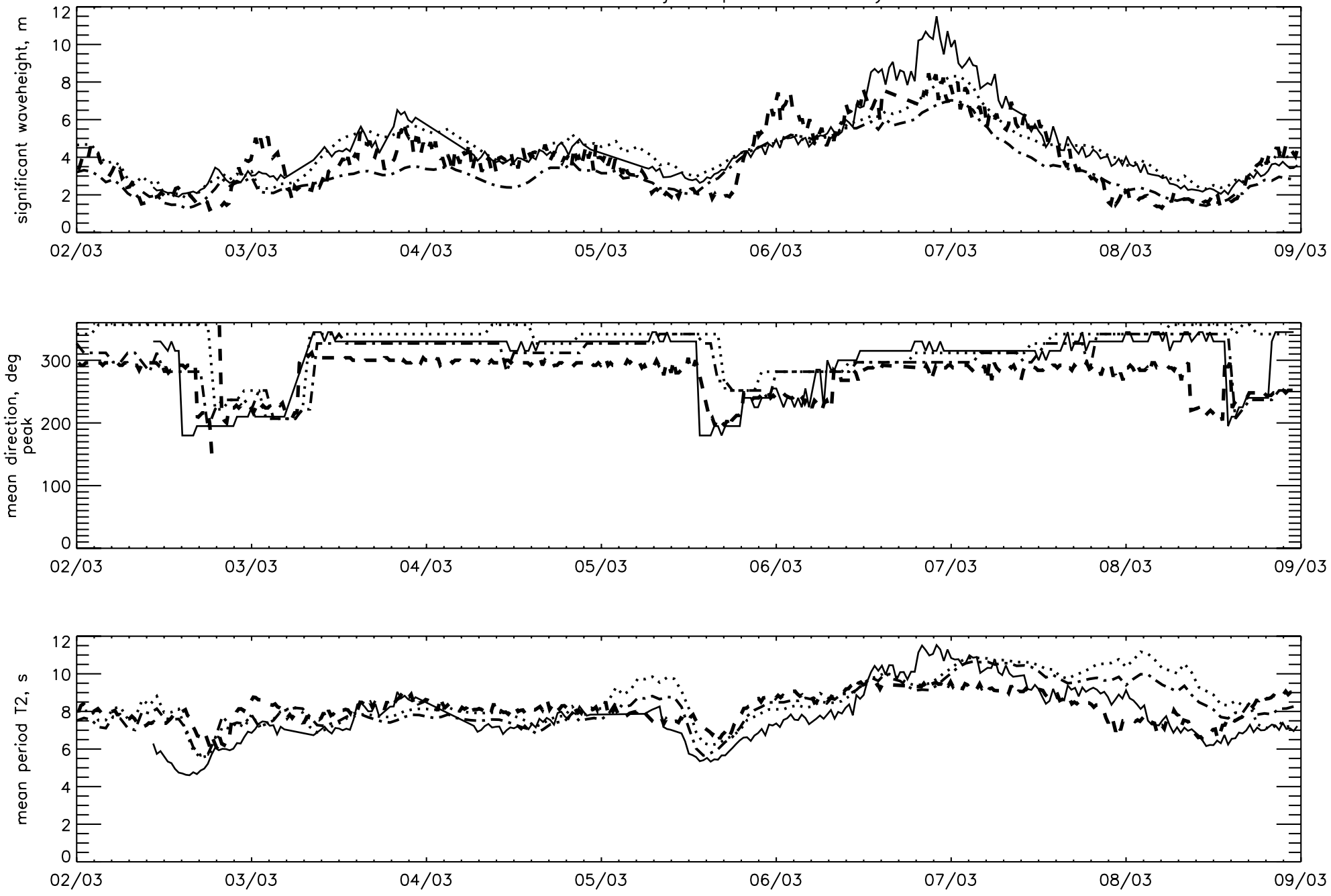

Fig. 6. Wave parameter comparisons at the Hellisoy WaMoS position. Buoy (solid line), WAM close to the buoy (dotted line), close to the WaMoS (dash-dot), WaMoS (thick dashed line). 
much more stable at Gijon. From the point of view of the intercomparisons, the Fedje data set provides an excellent opportunity to assess the data in storm conditions, whereas at Gijon, swell-dominated seas are the focus of the analysis.
As will be seen below, data were available more or less continuously from all instruments throughout the Fedje experiment Data coverage during the Gijon experiment is good although not as complete as at Fedje. In both cases, the WaMoS radars are not a $02 / 03 / 2000$ 15:00 WERA
$\mathrm{HS}=2.34 \mathrm{~T} 1=5.3$

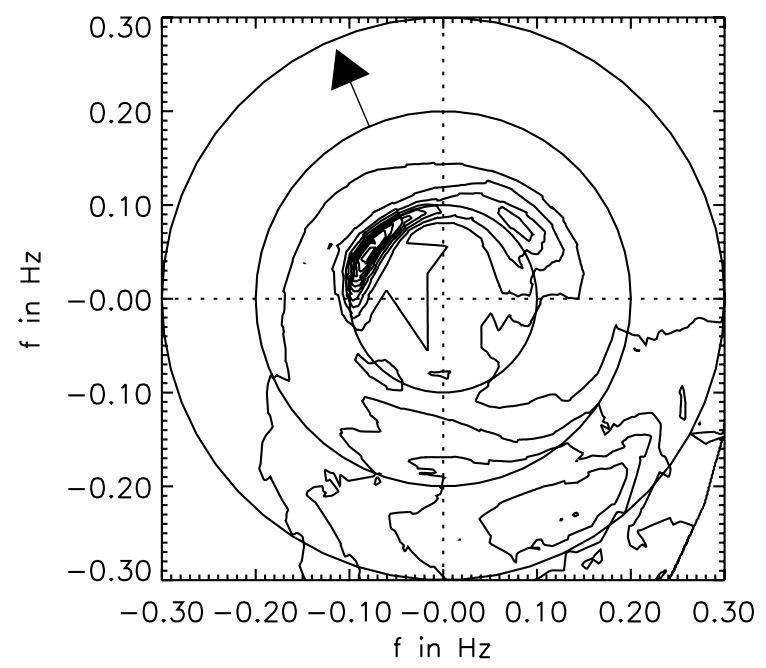

WAM 15:00 near buoy $\mathrm{Hs}=1.8 \mathrm{~T} 1=7.7$

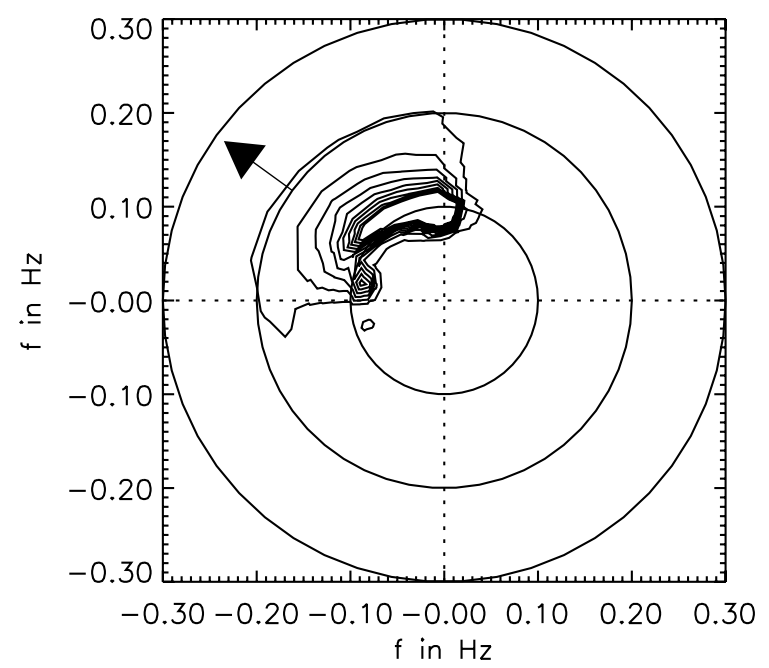

buoy 15:0

$\mathrm{Hs}=2.06 \mathrm{~T} 1=5.1$

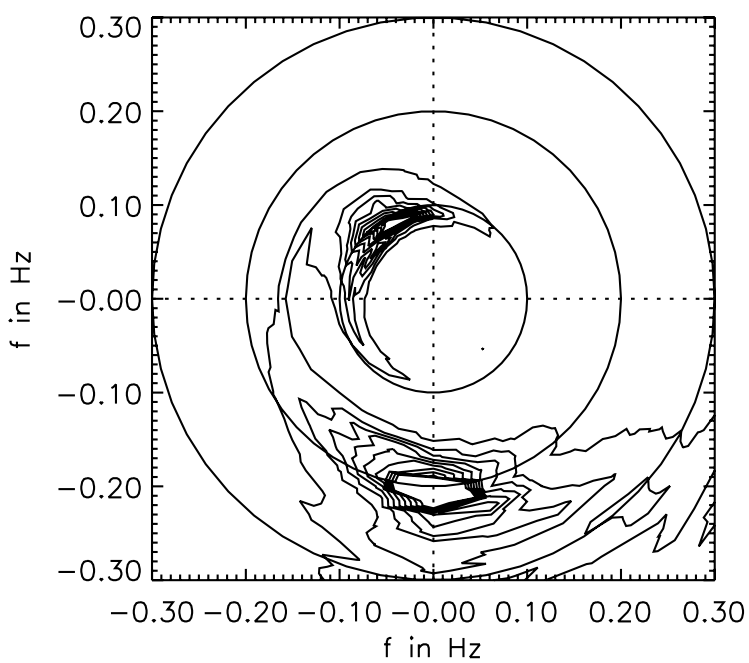

WaMoS Hellisoy 15:13 $\mathrm{Hs}=2.26 \mathrm{~T} 1=8.1$

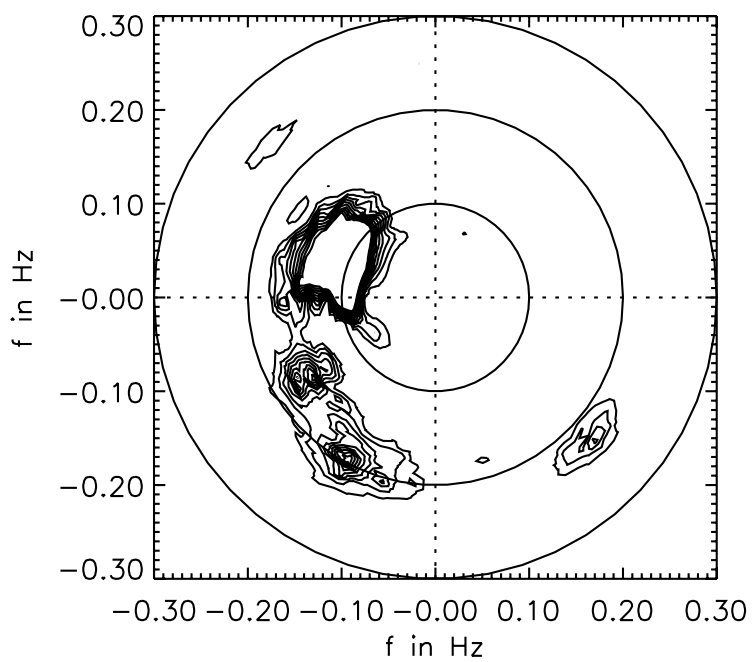

Fig. 7. Directional spectra response to changing wind directions on March 2, 2000: (a) $1500 \mathrm{~h}$, (b) $1800 \mathrm{~h}$ and (c) $2100 \mathrm{~h}$. In each case, WERA is top left, buoy is top right, WAM is bottom left and WaMoS is bottom right. The contours are drawn at 10 equal levels from 0.05 to 0.95 of the maximum energy in the WERA spectrum and indicate energy in directions from which the waves are coming. Arrows show wind directions (towards which the wind is blowing) measured by WERA and the one used in WAM. 

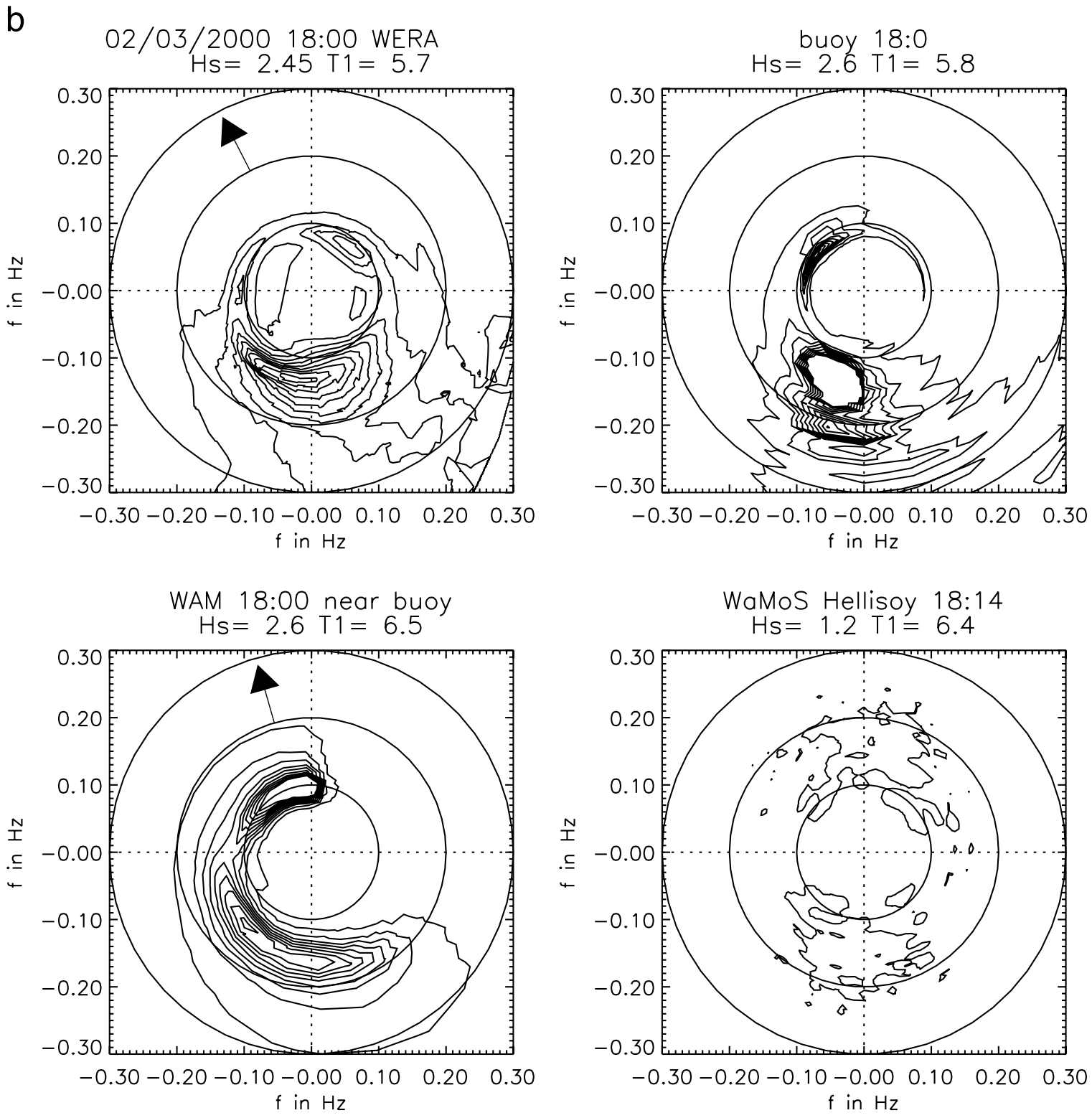

Fig. 7 (continued).

colocated, whereas the buoy, WERA and WAM (at Fedje) ones are. Wave heights are generally lower at Gijon consistent with the lower wind speeds. Because wind speeds were often low at Gijon, there are more gaps in the WaMoS coverage because the imaging mechanism requires the presence of short wind waves. As a result, there are a number of large wave-height swell events which are not imaged throughout.

\section{Comparisons}

\subsection{Fedje}

Fig. 3 shows frequency spectra (directional spectra integrated over direction), and Fig. 4 shows direction spectra (directional spectra integrated over frequency) throughout the experiment comparing 

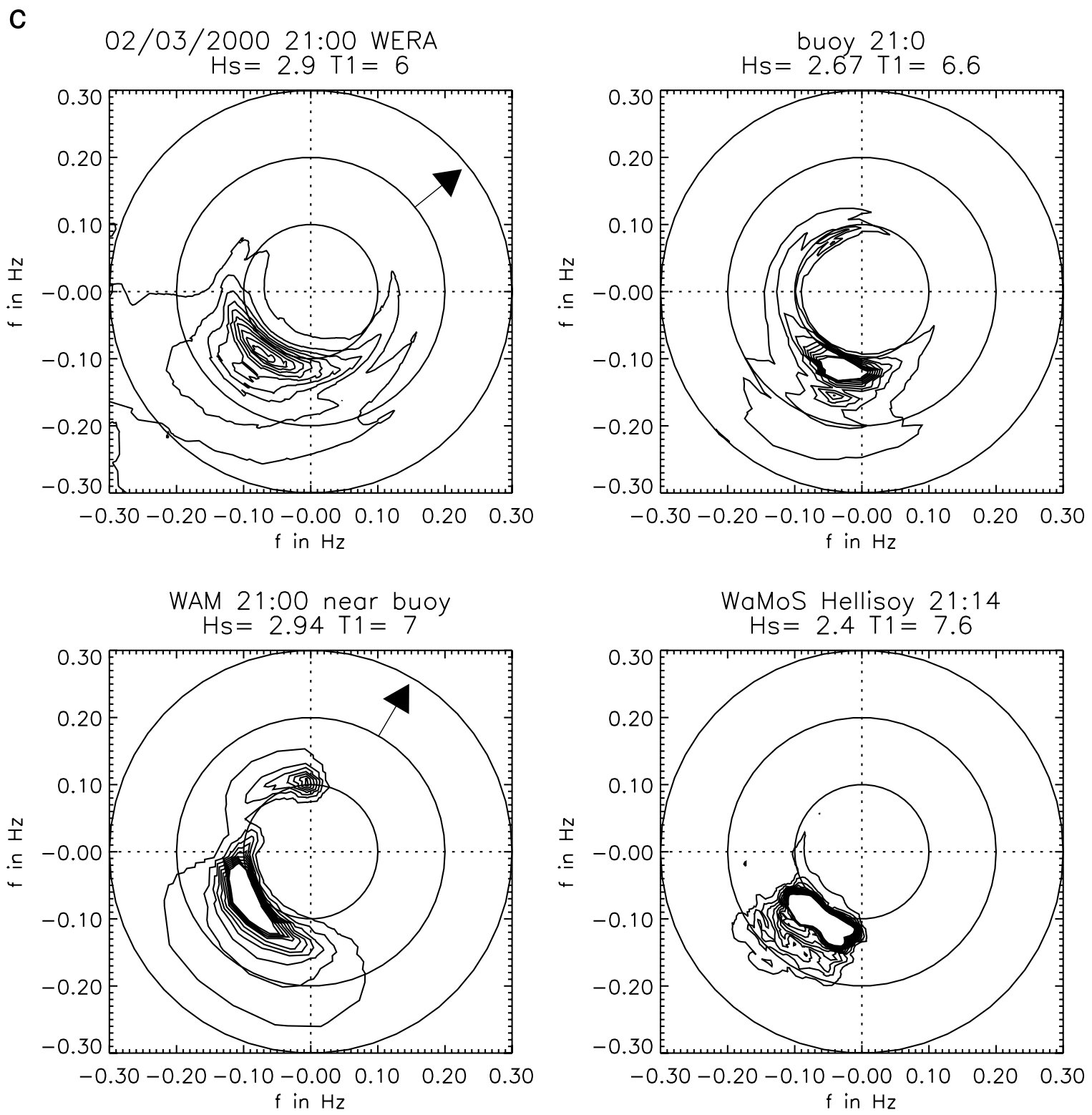

Fig. 7 (continued).

the WERA measurement at the buoy position, the buoy, WAM at position WAM2 and the WaMoS at Hellisoy. The essential features of the comparisons discussed in more details below are present in these figures. The temporal variability seen in the buoy data is well represented in all the other measurements most of the time; however, there are some differences in detail. In the higher sea events, the WERA measurement underestimates energy at the peak of the spectrum at the same time overestimating high-frequency energy. WERA shows more directional spreading compared to the others, and this is particularly apparent during the higher sea events. WaMoS measures the peak events well, but 
underestimates energy at frequencies above about $0.2 \mathrm{~Hz}$ throughout and, hence, does not measure low sea states well. The smoothness in the WAM spectra is partly due to the poorer temporal sampling; however, it otherwise shows impressive qualitative agreement with the buoy data.
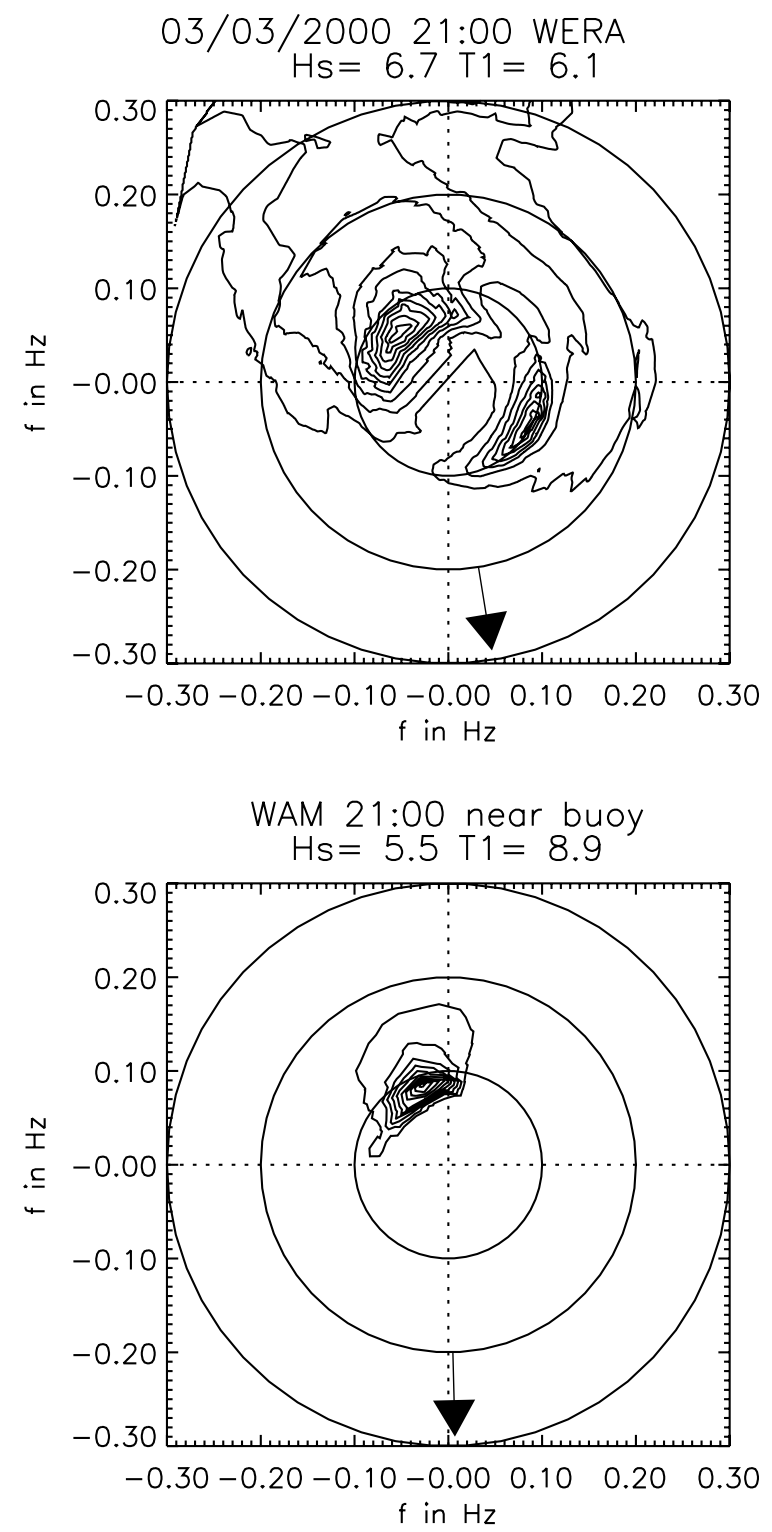

In this paper, we concentrate on the period March 2-9, which includes the highest storm event of March 6-7. Additional comparisons can be found in Wyatt and Green (2001) and Wyatt et al. (2002). Fig. 5 shows the comparisons of WERA, buoy and WAM significant wave height,
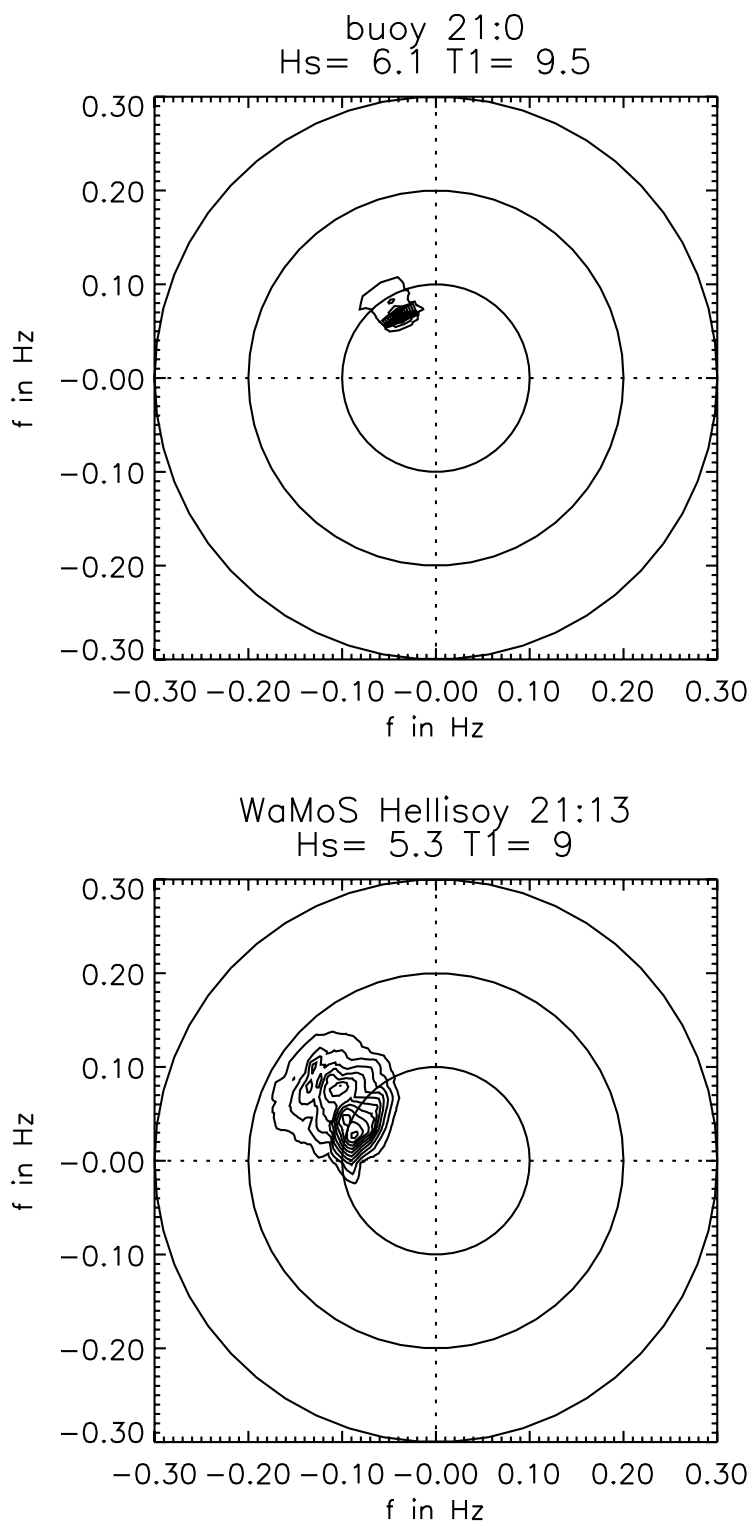

Fig. 8. Directional spectra on March 3, 2000 at $2100 \mathrm{~h}$. Same arrangement as Fig. 7. In this figure, each spectrum is scaled to its own maximum energy level. 
mean period, mean direction and mean directional spreading at the buoy location for this period. The mean period is determined using the first moment of the energy spectrum, and the directional parameters are determined using

$\theta_{\text {mean }}=\tan ^{-1} \frac{\int_{f_{1}}^{f_{2}} \sin \theta_{\mathrm{m}}(f) E(f) \mathrm{d} f}{\int_{f_{1}}^{f_{2}} \cos \theta_{\mathrm{m}}(f) E(f) \mathrm{d} f}$

for mean direction, and a similar expression for mean spread. Significant wave-height estimates compare well (see Table 1 for a quantitative evaluation) although there are no WERA measurements of sufficiently good quality at the height of the storm during the night of March 6-7, and there is some disagreement in maximum amplitude between the buoy and WAM (discussed further in Section 4.4). The significant underestimation of mean period by WERA is directly related to the overestimation of high frequency amplitude already referred to.

WERA directions are slightly noisier than those of the buoy and WAM but, nonetheless, agree well. Most of the noise in WERA directions is at the low-frequency end of the spectrum (Wyatt and Green, 2001), which is also the frequency range containing the spectral peak. Note the differences between the buoy and WAM, even taking into account that the WAM data presented here are only available every $3 \mathrm{~h}$, during the two periods of directional change on the afternoons of March 2 and 5. The first of these is discussed further below.

Because of the sheltered locations of the WaMoS measurements, they have not been included in the above comparison. Fig. 6 shows significant wave height, mean direction determined from the directional spectrum integrated in frequency (i.e., the peaks seen in Fig. 4) and mean period determined using the second moment of the frequency spectrum measured by the Hellisøy WaMoS and compared with the WAM estimates at the same location. The parameters used for this comparison are different from those discussed above because WAM spectra were not stored at the Hellisøy location. Also included are the WAM estimates at the site of the buoy and the buoy data. The reason for this was to see if differences between buoy and WaMoS are also reflected in the WAM model. As can be seen, this is not the case. For example, during the period March $3-5$, the buoy mean direction is from west of north, i.e., a direction from which the WaMoS measurement location is sheltered. WaMoS shows a more westerly direction consistent with this sheltering, whereas WAM estimates at both locations are rather similar. The implication is that WAM is not responding well to the details of the local coastline.

Fig. 7 shows directional spectra responding to the change in wind direction on March 2. Fig. 7(a) shows the situation a few hours after the wind has turned to a southeasterly direction showing the continued existence of swell from the northwest, but both WERA and buoy showing wave development in response to the new wind direction. Three hours later (b), the wind wave response is seen in the WAM spectrum; however, the swell measured by the buoy is much lower in amplitude. WERA is not showing the swell contribution at all although it is rather noisy at low frequencies. The sea at the

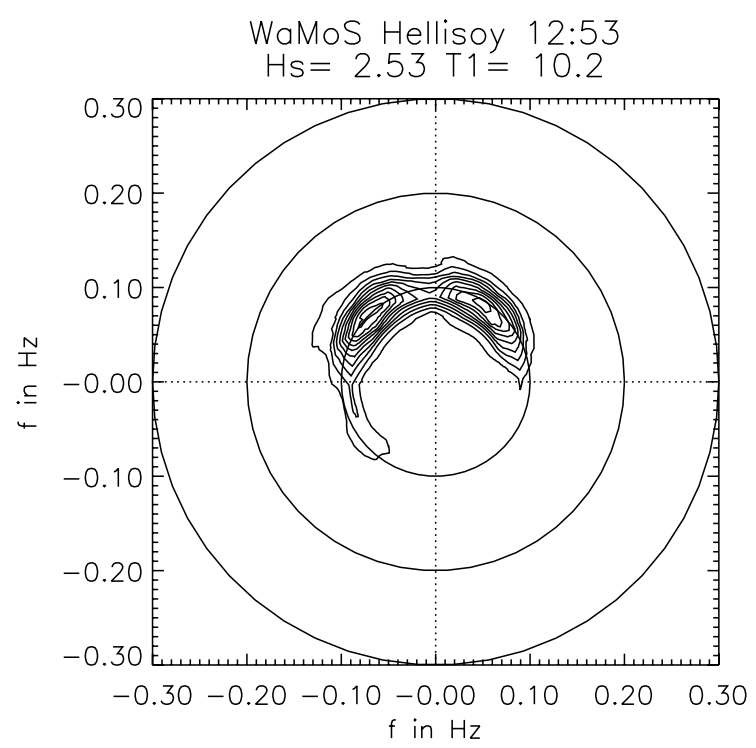

Fig. 9. Directional spectrum measured by WaMoS at Nordoy on March 5, 2000, 1253 h. Same energy levels as Fig. 8, i.e., normalised to the maximum in the spectrum. 
WaMoS location is very fetch-limited with this wind direction; hence, wave conditions are below the threshold for measurement. By $2100 \mathrm{~h}$ (c), the wind has changed to a southwesterly direction and all measurements are showing the response in much the same direction. There is still some evidence of residual swell in the WAM spectrum and perhaps also in the buoy spectrum, but at a much lower amplitude.

Evidence of refraction of waves propagating from the northwest as they approach the coast at Hellisøy is seen in Fig. 8. WERA, buoy and WAM all show the northwesterly waves, whereas the WaMoS measurement shows the waves are from a more westerly direction at that location. The WERA spectrum includes a component apparently propagating from the coast at $0.1 \mathrm{~Hz}$ and probably due to antenna sidelobe contamination. This is another example that explains the noisy mean directions at low frequencies. Other examples of coastal effects have been seen in the WaMoS data. For example, Fig. 9 shows evidence of reflection of wave energy at the Nordoy location due to the islands in the vicinity.

\subsection{Gijon}

In contrast to the Fedje experiment, the Gijon experiment was dominated by swell conditions, and we concentrate here on the period October 18-26, which includes two swell events with particularly high significant wave heights. Fig. 10 shows comparisons of significant wave height, mean period, direction and spread at the buoy position during this period. As can be seen, there are a number of gaps in both WERA and WaMoS coverage. The largest gap in the WERA data (October 21) was due to a computer-hacker problem apart from which measurements were more or less continuous. In the WaMoS case, a new quality criterion had been implemented that took account of the low sea-state limitations identified at Fedje (see Fig. 7(b)). This resulted in several gaps in coverage that are discussed further below. When the instruments are working, they both show reasonable agreement with buoy significant wave height. WERA again overestimates high frequency and underestimates peak frequency amplitude compared to the buoy during the high wave height events leading to an underestimation of mean period although it is interesting to note that WERA and WaMoS periods appear to agree for much of the time.

Fig. 11 shows WaMoS measurements during the period October 18-22 together with wind speed and rain information used to understand the reasons for poor quality in some WaMoS data. Those WaMoS measurements that did not pass the internal quality control are shown with light dots. These coincide with periods of low wind speed $(<3 \mathrm{~m} / \mathrm{s})$. These periods are marked in the time series with a lightgrey background. The mapping of the sea surface with the WaMoS radar is based on the backscatter of the emitted radar signal by the sea-surface roughness. This roughness (ripple of the order of a few centimetres in wavelength) is commonly generated by the local wind. When the wind speed is too low to generate sufficient surface roughness for the radar backscatter, longer waves are also not detectable by the radar. The quality control procedure checks whether the measured radar backscatter is sufficient. Although significant wave height was sometimes higher than the minimum for accurate measurement identified at Fedje $(\sim 2 \mathrm{~m})$, this was due, during this time period at Gijon, to swell in the presence of very low wind speeds; hence, the backscatter was not sufficient. Another factor that has been shown to affect the accuracy of the WaMoS measurement is heavy rain that also influences the sea surface roughness and, hence, affects the radar measurements. The darker grey area in Fig. 11 (October 21) shows a period of rain. The horizontal shaded area indicates the wave-height interval $(<1.2 \mathrm{~m})$ where the modulation of the radar backscatter due to the longer waves is too low to perform good sea-state measurements. Notice that this limit is lower than the $2 \mathrm{~m}$ identified at Fedje. This is probably related to differences in height above sea level of the systems or other radar parameters.

Breaking waves and white water have different backscatter properties so that the standard algorithms for significant wave-height retrieval cannot be applied. This explains some difference between WaMoS and buoy significant wave-height measurements during the storm period in November. Similar affects were also occasionally seen at Fedje, in particular, at the Nordoy site, which was in the vicinity of rocky outcrops. The 

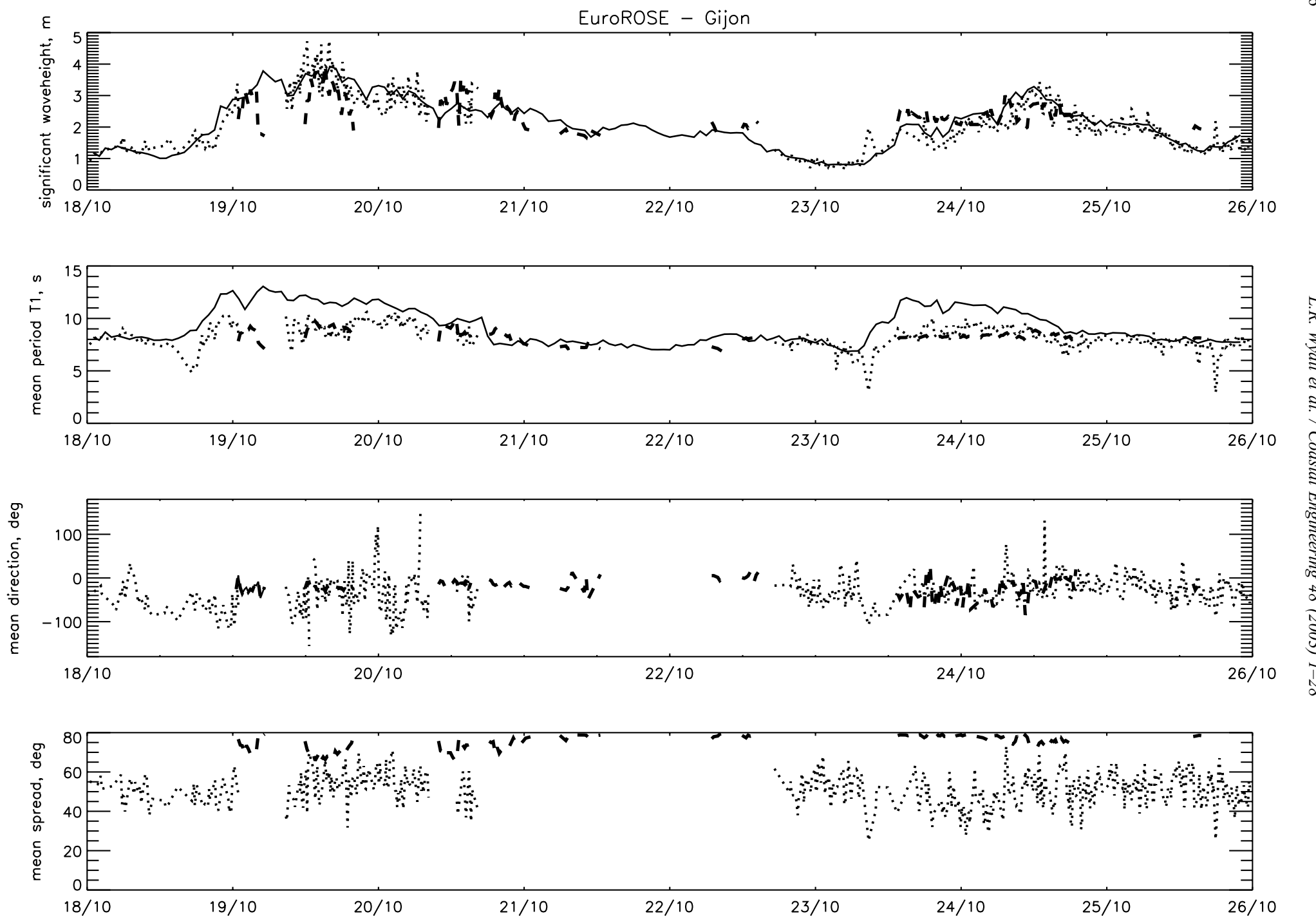

Fig. 10. Wave parameters measured during the Gijon experiment. The WERA (dotted) measurements are at the location of Waverider 2 (solid line) (see Fig. 2) and the WaMoS at Torres (thick dashed line). 

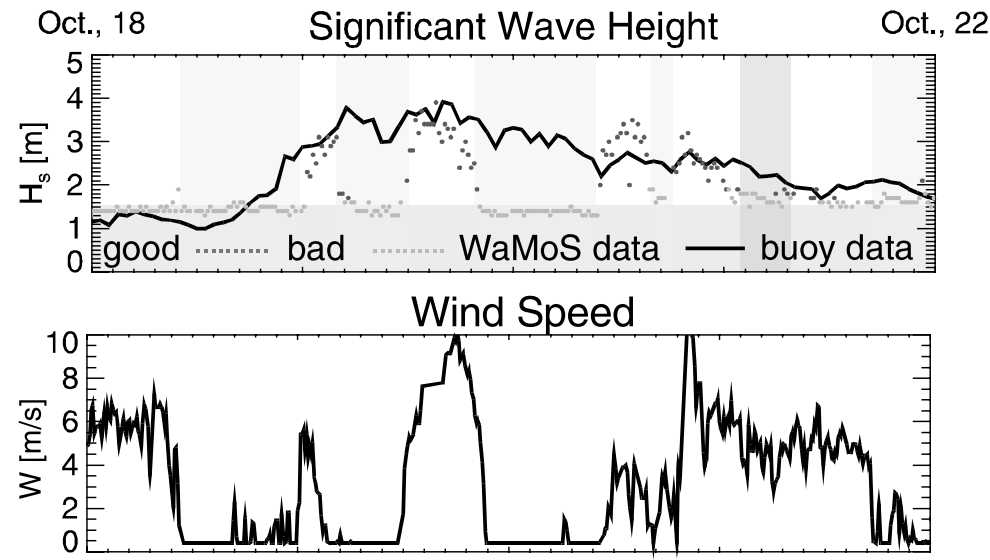

Rain Rate

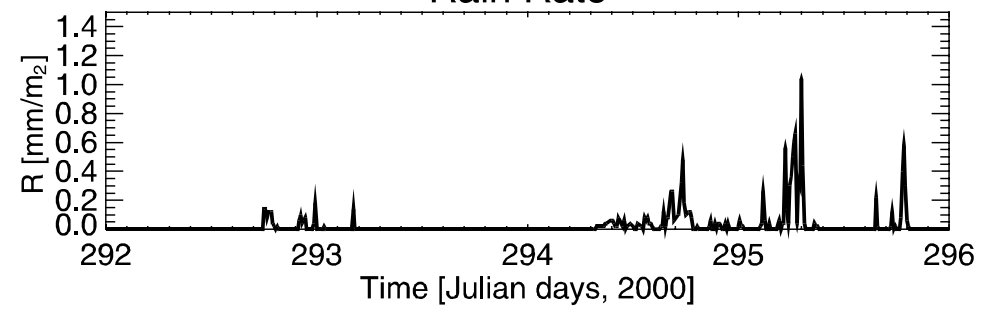

Fig. 11. WaMoS (dots) and buoy (solid line) significant wave height measurements at Gijon. Light dots show WaMoS measurements that fail the quality control procedure. Middle panel shows wind speed and bottom panel rain rate.

measurement of the other wave properties, such as wave direction and period, are more or less unaffected by this as long as the general wave propagation is unaffected by the breaking.

WERA mean directions (and mean directions over limited frequency bands not shown here) are rather noisier than at Fedje probably due to the location of the measurement being used for the comparison. In all previous work, comparisons have been made with buoys located in the centre of the radar coverage, where sidelobe effects are minimised and signal levels from both radars are optimised. At Gijon, the buoy is located at long range from the Peñas WERA and at a location where the sidelobe levels from that radar could be expected to be a problem. The variation in accuracy of the WERA measurements with position has also been identified in a detailed comparison with the SWAN wave model (Caires, 2000).

Comparisons of WERA and WaMoS directional spreading at Fedje have not been presented here, but are very different from the Gijon results shown in Fig. 10. These show very broad mean spreading for
WaMoS which contrasts with very narrow mean spreading at Fedje. This may be related to breaking of the swell at the WaMoS measurement positions due to the shallower water depth at Gijon and to the low wind speeds. These factors clearly influence the shape of the directional spectrum and, hence, the mean directional spreading, as is discussed further below. During November, when wind speeds were generally greater, WERA and WaMoS measure similar spreads again in contrast to Fedje, where the WERA measurements were always broader than WaMoS.

It was noted above that WERA and WaMoS mean periods agree quite well, whereas the buoy period is generally higher. The reason for this can be seen in Fig. 12, which shows $E(f), \theta_{\mathrm{m}}(f)$ and $\sigma_{\mathrm{m}}(f)$ during the first swell event seen in Fig. 10. Note that the buoy is only close to the measurements near Torres and the WERA and WaMoS are only colocated at Peñas. The measurements on October 19, 2000 at $\sim 1700 \mathrm{~h}$ were taken at the peak of the event. At Torres, both radars have a similar frequency spectrum with a peak amplitude much lower than that of the buoy and a larger 
amplitude a higher frequencies leading to lower-mean periods. At the later time, October 20, 2000 at $\sim 1200$ $\mathrm{h}$, the radar peak amplitudes are a little closer to that of the buoy leading to similar mean periods as seen in
Fig. 10 at this time. Note the change in high-frequency direction measured by WERA between these two times. This shows the influence of the local wind. WaMoS cannot measure at the high frequencies that

a

$19 / 10 / 2000 \quad 17: 00 \quad E$

WaMoS penas 17:13

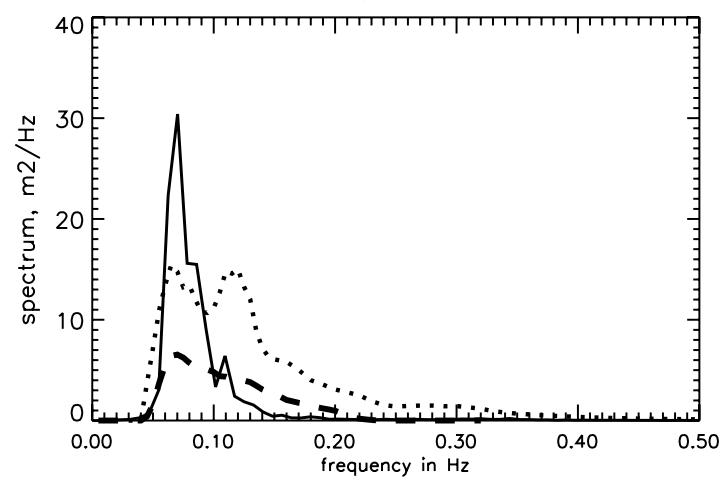

19/10/2000 17:00 B

WaMoS torres 17:13
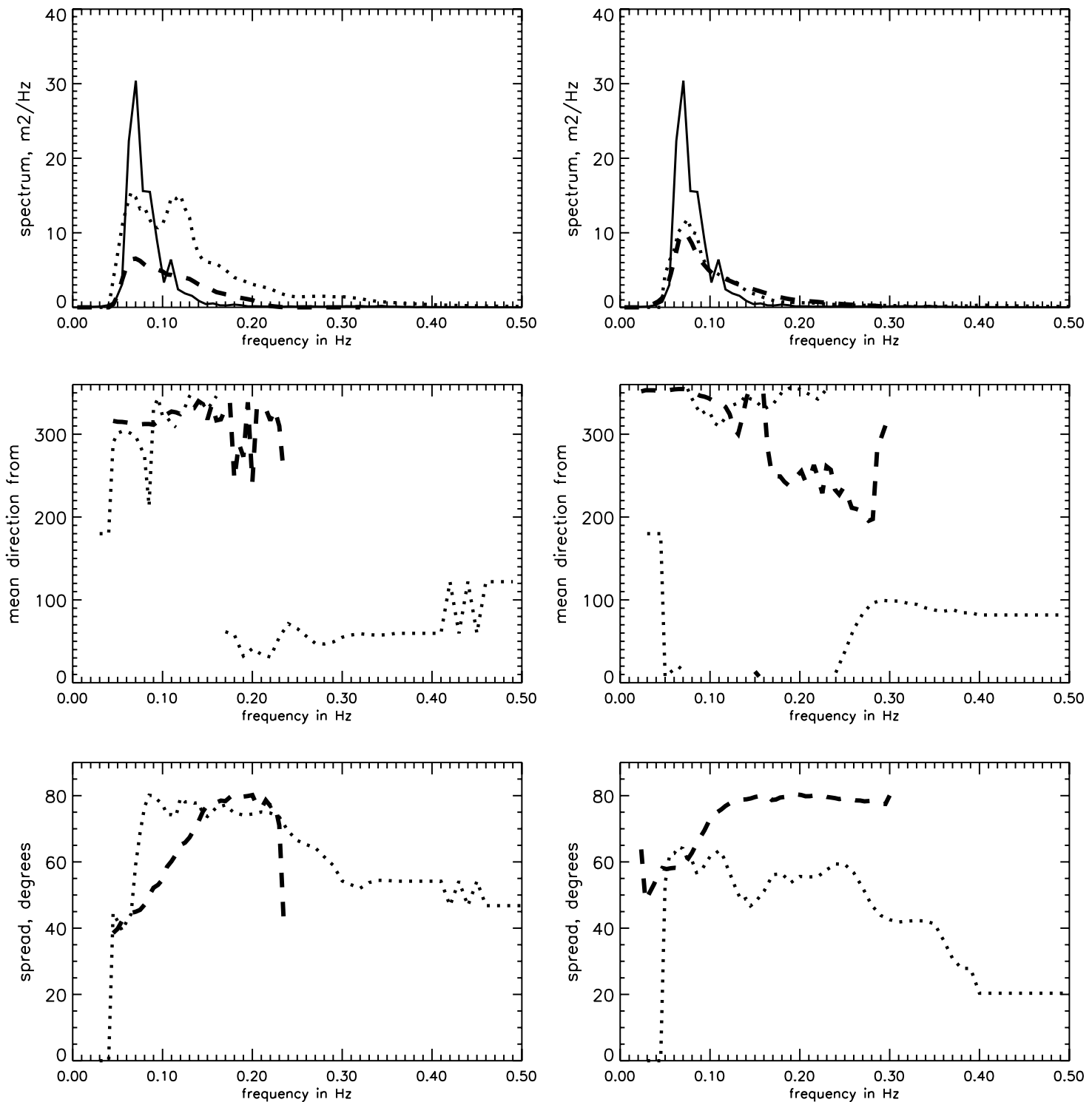

Fig. 12. Parametric directional spectra measured by Waverider 2 (solid line, amplitude only), WaMoS (thick dashed line) at Peñas (left) and Torres (right) and WERA (dotted line) close to the WaMoS measurement sites. (a) October 19, 2000 at $\sim 1700$ h and (b) October 20,2000 at $\sim 1200 \mathrm{~h}$. 
b $20 / 10 / 2000 \quad 12: 00 \quad E$

WaMoS penas 12:14
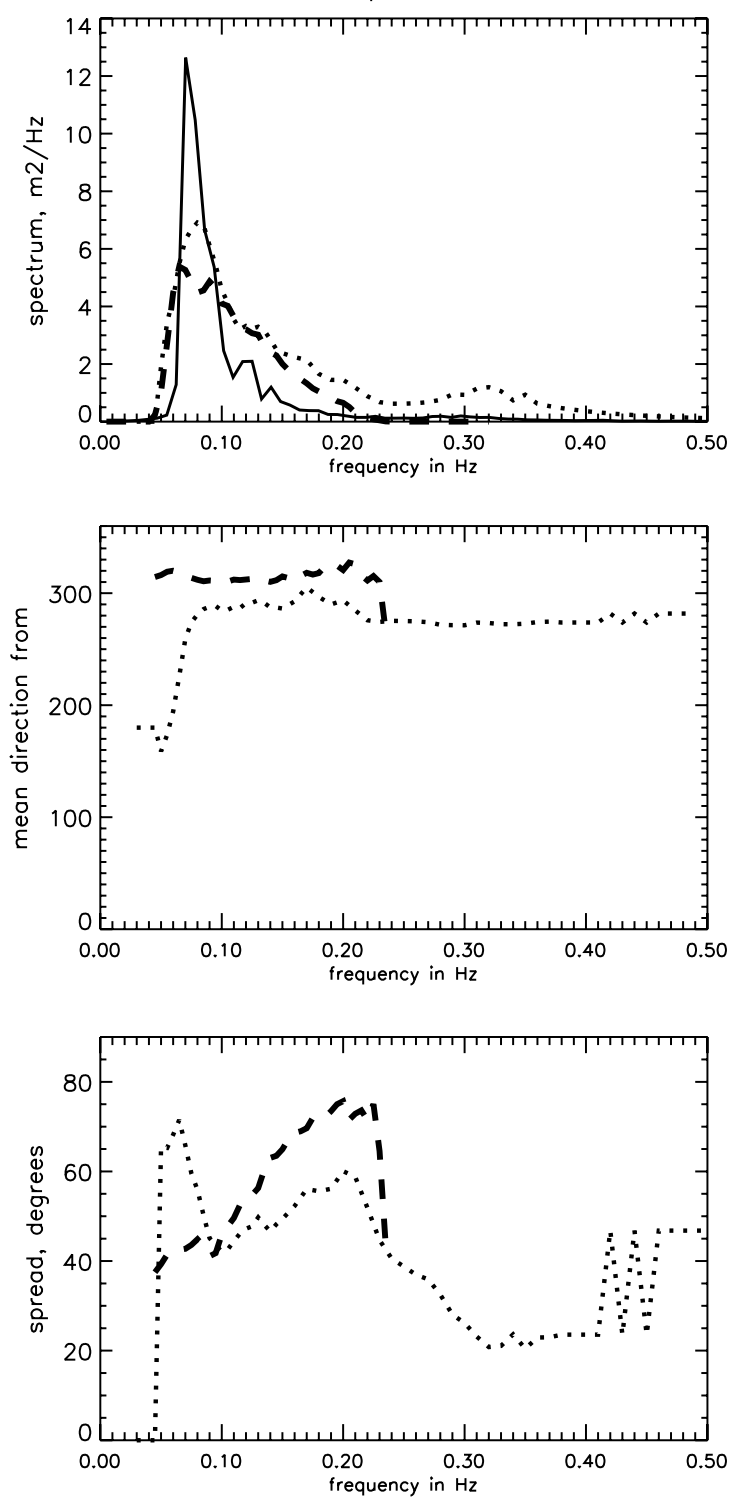

$20 / 10 / 2000 \quad 12: 00 \quad B$

WaMoS torres 12:13
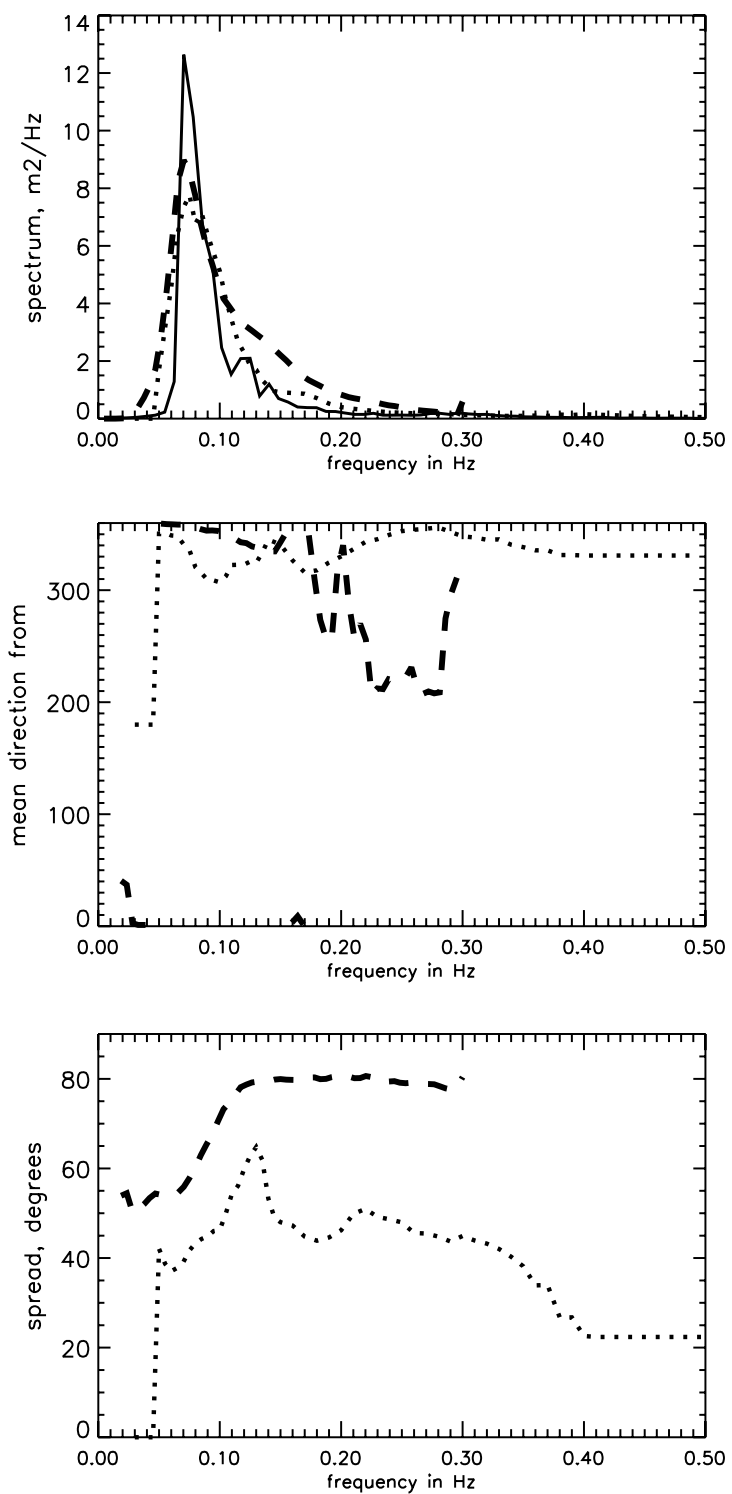

Fig. 12 (continued).

are responding to the wind. At Torres, the WaMoS measurements are rather noisy at frequencies greater than about $0.15 \mathrm{~Hz}$. Fig. 13 shows that the swell peak is clearly defined in the WaMoS spectra; however, there is noise at low amplitude contributing to the high-frequency variability and, hence, also to the broad overall directional spreading referred to above. The WERA spectra in this figure show some of the spurious features already identified at Fedje which contribute to the scatter in mean direction and the broad directional spreading seen in the parametric plots. 


\subsection{Statistics}

To provide a measure of the difference between two measurements, we use, for linear parameters, e.g., wave height and period, the relative difference and its standard deviation and, for circular parame- ters, e.g., mean direction and spread, the mean difference and its standard deviation. Correlation coefficients provide a broad qualitative assessment of the comparisons. The appropriate choice of such statistical measures is discussed in Krogstad et al. (1999). These statistics have been shown (Wyatt, a

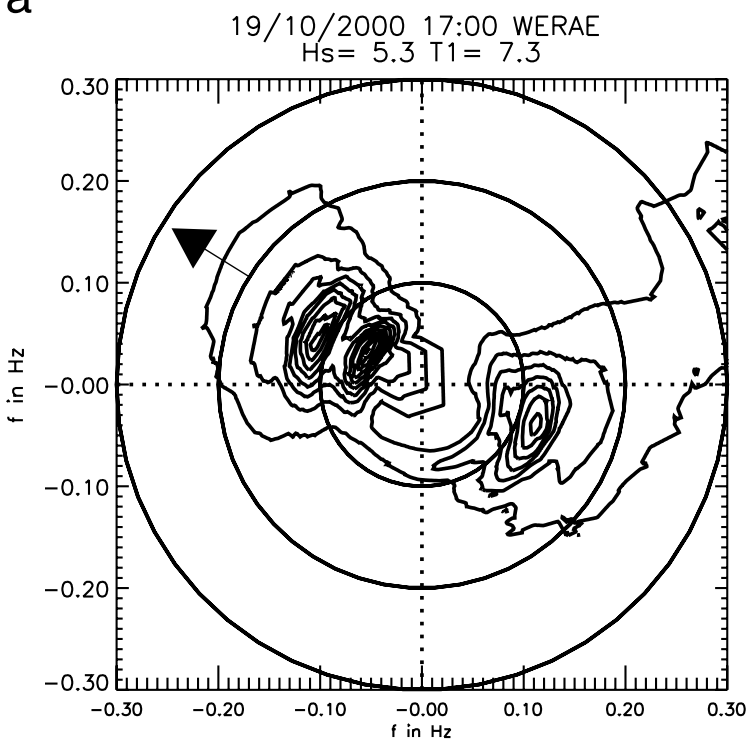

WaMoS penas $17: 13$

$\mathrm{Hs}=3 \mathrm{~T} 1=9.2$

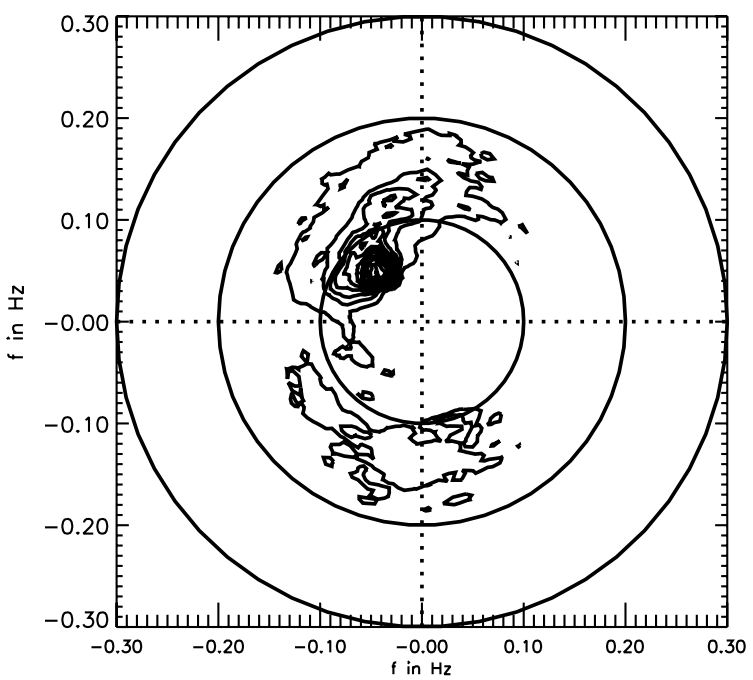

19/10/2000 17:00 WERAB

$\mathrm{Hs}=3.4 \mathrm{~T} 1=8.6$

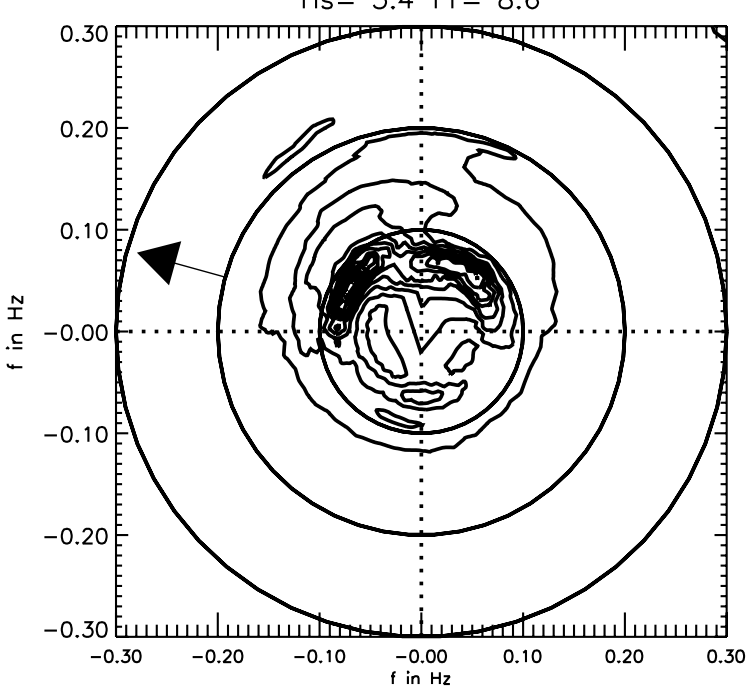

WaMoS torres 17:13

$\mathrm{Hs}=3.3 \mathrm{~T} 1=9.2$

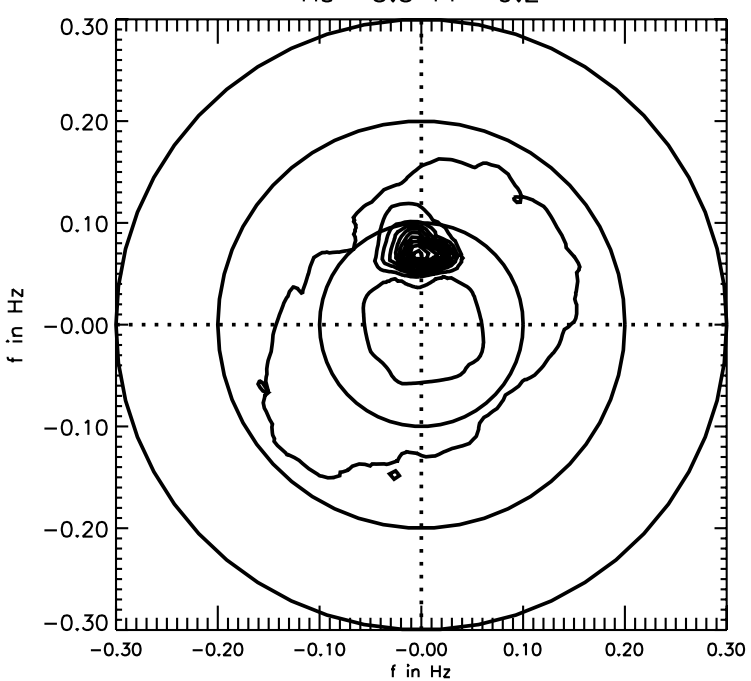

Fig. 13. Directional spectra measured by WERA (above) and WaMoS below at the same locations and times as Fig. 12a,b. Maximum amplitudes are in the directions from which the waves are propagating and contours are at 10 equal intervals from 0.05 to 0.95 of the peak in each spectrum. WERA measured wind directions (towards which the wind is blowing) are shown with arrows. 
b

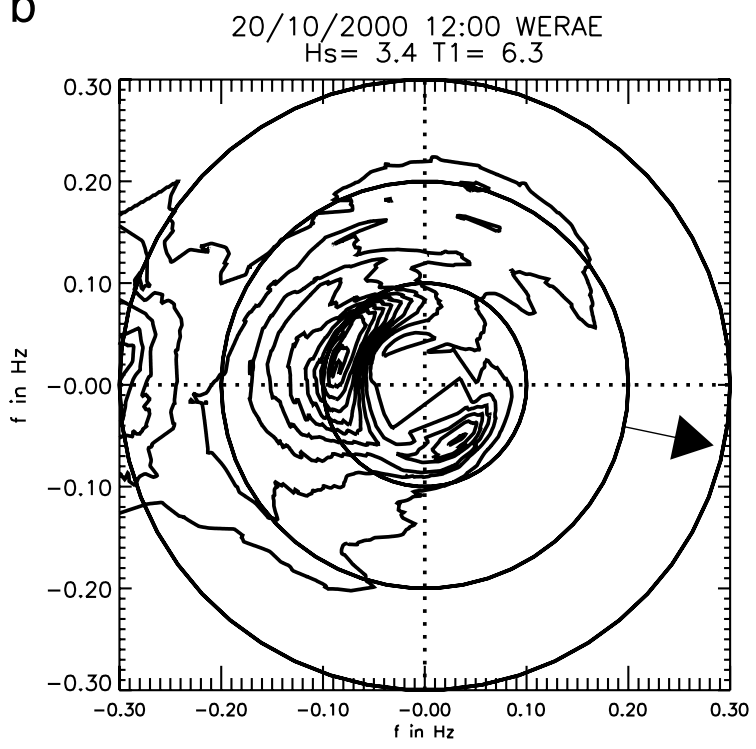

WaMoS penas $12: 14$

$\mathrm{Hs}=2.7 \mathrm{~T} 1=9.3$

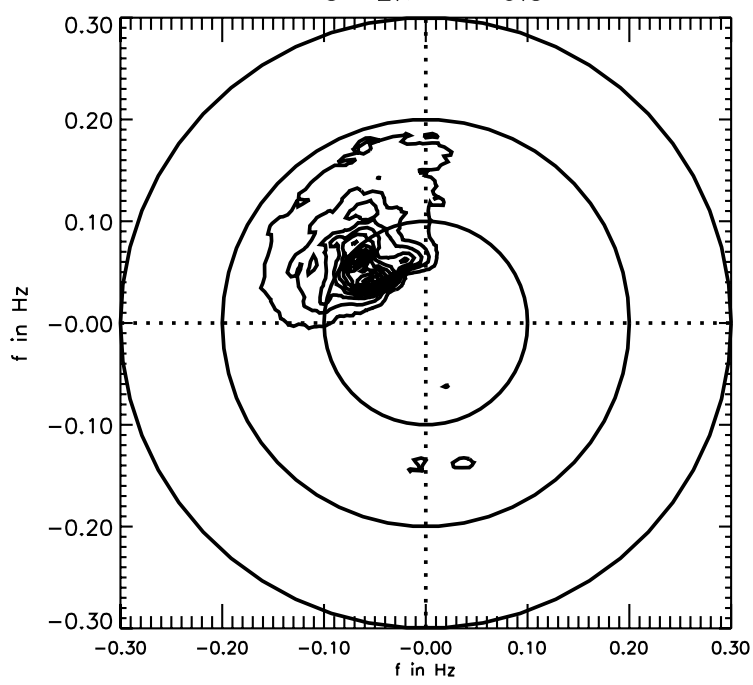

20/10/2000 12:00 WERAB

$\mathrm{Hs}=2.8 \mathrm{~T} 1=8.8$

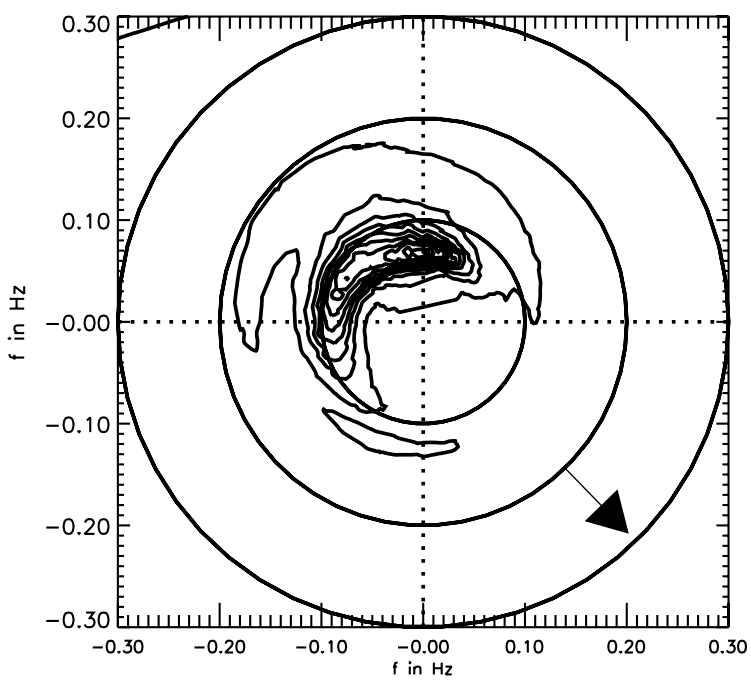

WaMoS torres $12: 13$

$\mathrm{Hs}=3.16 \mathrm{~T} 1=9.3$

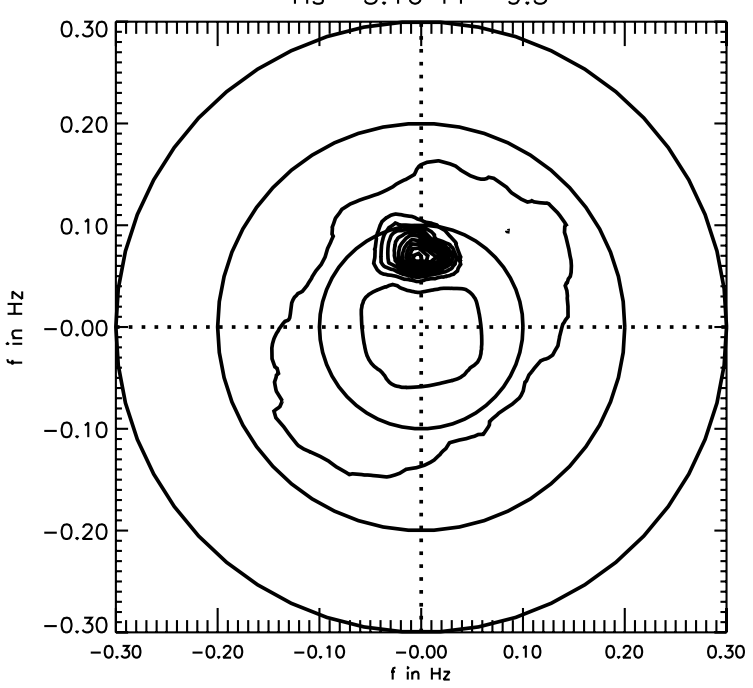

Fig. 13 (continued).

2002) to give quantitative information that is roughly the same as that which is obtained using a more complex analysis that takes into account different variances in the two measurements. These variances have to be estimated from the data (Caires, 2000) or obtained using the theory of sampling variability (as has been done for buoy data) or through the use of
Monte Carlo simulations (as has been done for HF radar data, Sova, 1995). This work has also shown that variances estimated from the data for the buoy and WERA wave measurements at Fedje are very different from the theoretical estimates; thus, there is some uncertainty in the interpretation of the more complex approach. As a result, only the recommen- 
a EuroROSE - Fedje at buoy position

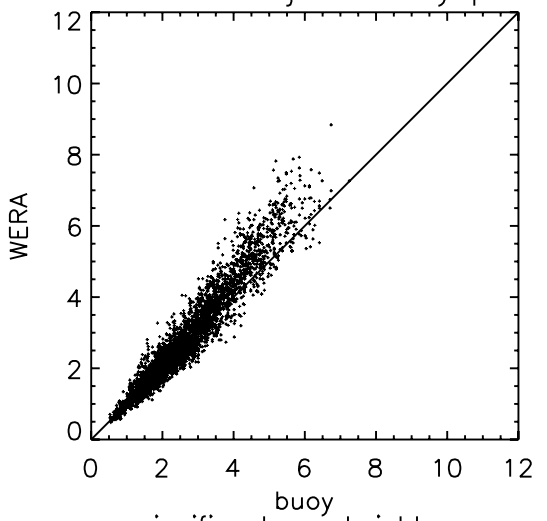

significant waveheight, $m$

b

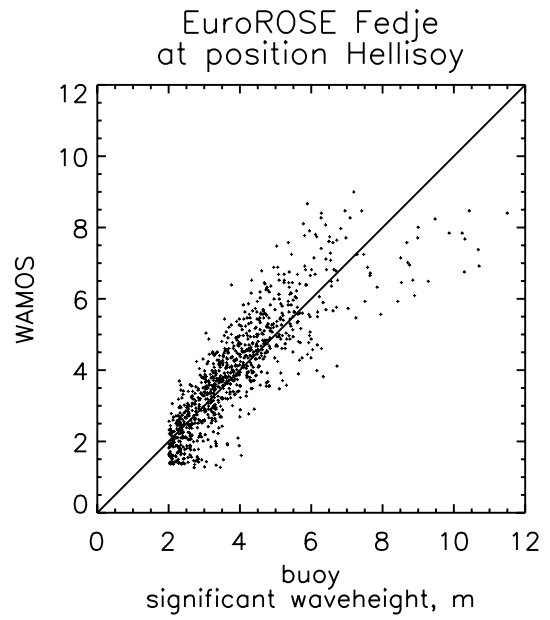

C EuroROSE - Fedje at buoy position

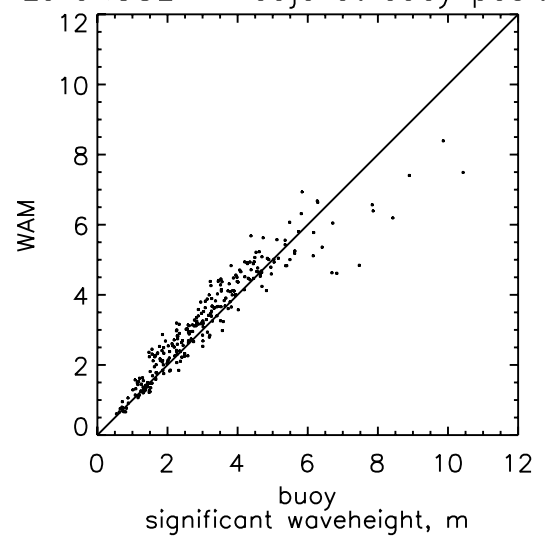

Fig. 14. Scatter plots of significant wave height comparisons at Fedje of (a) WERA, (b) WamoS and (c) WAM with the buoy.

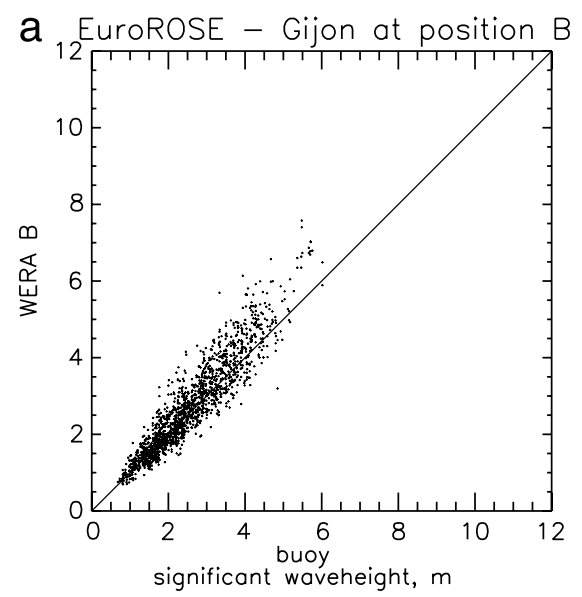

b EuroROSE - Gijon at position $\mathrm{B}$

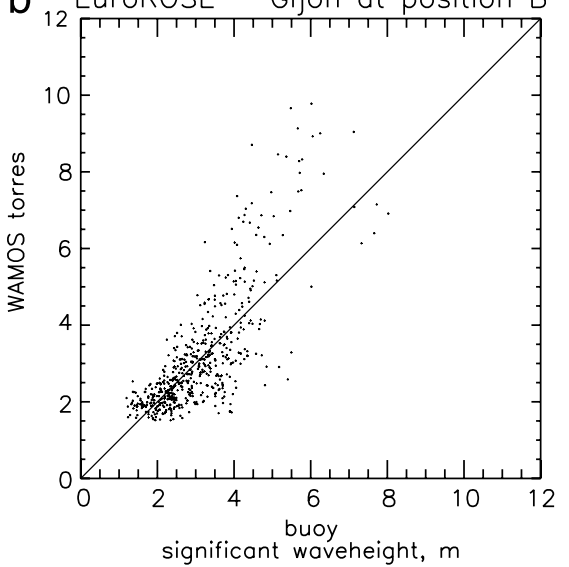

C EuroROSE - Gijon at position E

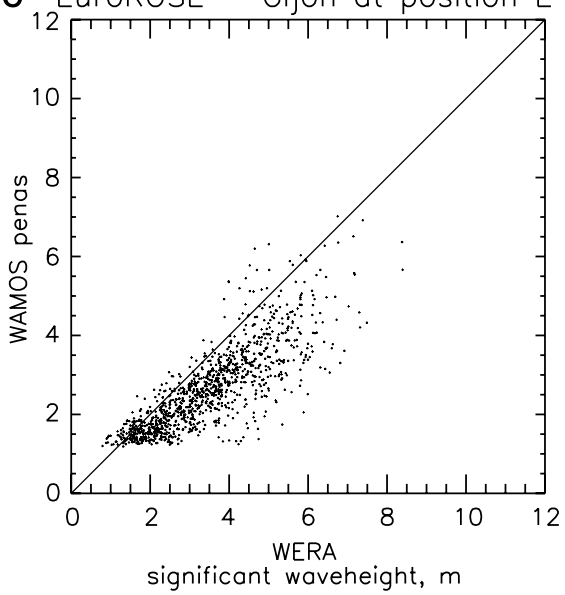

Fig. 15. Gijon significant wave height scatter plots. (a) WERA vs. buoy at the location of the buoy, (b) WaMoS, located about $4 \mathrm{~km}$ inshore, compared to the buoy and (c) Peñas WaMoS compared to the colocated WERA. 
Table 2

Fedje WaMoS, WAM and buoy parameter comparisons

\begin{tabular}{|c|c|c|c|c|c|c|c|}
\hline \multirow[t]{2}{*}{ Wave parameter } & \multirow{2}{*}{$\begin{array}{l}\text { Frequency } \\
\text { range }\end{array}$} & \multicolumn{2}{|c|}{ WaMoS/buoy } & \multicolumn{2}{|c|}{ WaMoS/ localWAM } & \multicolumn{2}{|c|}{ WAM at buoy/buoy } \\
\hline & & $\mathrm{cc}$ & $m(\mathrm{sd})$ & $\mathrm{cc}$ & $m(\mathrm{sd})$ & $\mathrm{cc}$ & $m(\mathrm{sd})$ \\
\hline Hs & Full range & 0.89 & $5.2 \%(30.8 \%)$ & 0.9 & $23.6 \%(47.3 \%)$ & 0.9 & $-12.2 \%(21 \%)$ \\
\hline $\begin{array}{l}\text { Second moment } \\
\text { Period }\end{array}$ & Full range & 0.59 & $15.4 \%(21.6 \%)$ & 0.53 & $-0.3 \%(13.0 \%)$ & 0.63 & $17.5 \%(22.1 \%)$ \\
\hline Direction & $\begin{array}{l}\text { Peak from 1D } \\
\text { direction spectrum }\end{array}$ & 0.4 & $-20.2^{\circ}\left(49.7^{\circ}\right)$ & 0.39 & $-9.8^{\circ}\left(44.3^{\circ}\right)$ & 0.62 & $-8.9^{\circ}\left(35.4^{\circ}\right)$ \\
\hline
\end{tabular}

cc-Correlation coefficient; $m$-Mean; sd-Standard deviation.

ded standard statistics will be used here to provide a quantitative measure of the differences between the measured and modelled data. These are presented in tables below and discussed in Section 4. Scatter plots of significant wave height are shown in Fig. 14 for Fedje and in Fig. 15 for Gijon.

The WERA, WAM and buoy measurements in Table 1 are colocated within about $2 \mathrm{~km}$. Table 2 shows the WaMoS comparisons with the colocated
WAM and with the buoy. For these, all cases with significant wave height $<2 \mathrm{~m}$ are excluded, and only those with peak propagation directions between $180^{\circ}$ and $300^{\circ}$ are included to exclude cases subject to sheltering and fetch limits for a fairer comparison with the buoy. The WAM at the buoy location are also compared with the buoy in this table for reasons discussed earlier. Tables 3 and 4 show the Gijon comparisons. The WERA and WaMoS are collocated

Table 3

Gijon parameter comparisons of WERA at the buoy location, Torres WaMoS and buoy

\begin{tabular}{|c|c|c|c|c|c|}
\hline \multirow[t]{2}{*}{ Wave parameter } & \multirow{2}{*}{$\begin{array}{l}\text { Frequency } \\
\text { range }\end{array}$} & \multicolumn{2}{|c|}{ WERA/buoy } & \multicolumn{2}{|c|}{ WaMoS/buoy } \\
\hline & & $\mathrm{cc}$ & $m(\mathrm{sd})$ & $\mathrm{cc}$ & $m(\mathrm{sd})$ \\
\hline \multirow[t]{5}{*}{$\overline{\mathrm{Hs}}$} & Full range & 0.93 & $5.9 \%(16.9 \%)$ & 0.78 & $2.8 \%(25.9 \%)$ \\
\hline & $\begin{array}{l}\text { Peak from 1D } \\
\text { frequency spectrum }\end{array}$ & 0.86 & $-36.7 \%(15.1 \%)$ & 0.72 & $-44.3 \%(19.5 \%)$ \\
\hline & $0.05-0.1$ & 0.92 & $17.5 \%(44.6 \%)$ & 0.72 & $11.3 \%(46.7 \%)$ \\
\hline & $0.1-0.2$ & 0.87 & $8.2 \%(21.7 \%)$ & 0.66 & $6.6 \%(34.4 \%)$ \\
\hline & $0.2-0.3$ & 0.79 & $50.4 \%(42.8 \%)$ & 0.46 & $48.2 \%(44.8 \%)$ \\
\hline $\begin{array}{l}\text { First moment } \\
\text { Period }\end{array}$ & Full range & 0.54 & $-15.4 \%(13.1 \%)$ & 0.31 & $-0.1 \%(15.2 \%)$ \\
\hline
\end{tabular}

cc-Correlation coefficient; $m$-Mean; sd—Standard deviation.

Table 4

Gijon parameter comparisons of WERA at the Peñas WaMoS measurement position, Peñas WaMoS and buoy

\begin{tabular}{|c|c|c|c|c|c|c|c|}
\hline \multirow[t]{2}{*}{ Wave parameter } & \multirow[t]{2}{*}{ Frequency range } & \multicolumn{2}{|c|}{ WERA@Peñas/buoy } & \multicolumn{2}{|c|}{ WaMoS/WERA@ @ Peñas } & \multicolumn{2}{|c|}{ WaMoS/buoy } \\
\hline & & $\mathrm{cc}$ & $m(\mathrm{sd})$ & $\mathrm{cc}$ & $m(\mathrm{sd})$ & $\mathrm{cc}$ & $m(\mathrm{sd})$ \\
\hline \multirow[t]{5}{*}{ Hs } & Full range & 0.94 & $23.5 \%(18.2 \%)$ & 0.82 & $-21.1 \%(18.6 \%)$ & 0.87 & $-3.8 \%(20.6 \%)$ \\
\hline & $\begin{array}{l}\text { Peak from } 1 \mathrm{D} \\
\text { frequency spectrum }\end{array}$ & 0.86 & $-28.9 \%(17.8 \%)$ & 0.69 & $-11.4 \%(30.3 \%)$ & 0.82 & $-44.1 \%(16.9 \%)$ \\
\hline & $0.05-0.1$ & 0.9 & $41.2 \%(61.4 \%)$ & 0.74 & $-7.8 \%(36.2 \%)$ & 0.86 & $9.5 \%(57.4 \%)$ \\
\hline & $0.1-0.2$ & 0.84 & $28.1 \%(28.7 \%)$ & 0.78 & $-14.6 \%(26.5 \%)$ & 0.76 & $14 \%(33.6 \%)$ \\
\hline & $0.2-0.3$ & 0.73 & $84.7 \%(60.4 \%)$ & 0.53 & $-62.6 \%(16.5 \%)$ & 0.26 & $-28.5 \%(27.3 \%)$ \\
\hline $\begin{array}{l}\text { First moment } \\
\text { Period }\end{array}$ & Full range & 0.43 & $-14.9 \%(13.6 \%)$ & -0.19 & $36.8 \%(27 \%)$ & 0.64 & $4.8 \%(12.3 \%)$ \\
\hline Direction & Full range & & & 0.24 & $12.9^{\circ}\left(33.5^{\circ}\right)$ & & \\
\hline
\end{tabular}

cc-Correlation coefficient; $m$-Mean; sd—Standard deviation. 
to within $2 \mathrm{~km}$ at Peñas. WERA and buoy are collocated at Torres and the WaMoS is about $4 \mathrm{~km}$ inshore.

\section{Discussion}

\subsection{WERA performance}

WERA significant wave height is very well correlated with that of the wave buoy, but has an upper limit (at the operating frequency used) of about $8 \mathrm{~m}$. Above $3 \mathrm{~m}$ significant wave height, the amplitude of high-frequency contributions is overestimated and that of low-frequency contributions underestimated, leading to a significant underestimation of mean period at higher wave heights. This is not an unexpected result and can be avoided by operating at a lower radio frequency. Other ideas for dealing with these problems are being investigated. Mean direction estimates correlate well with the buoy, but are rather noisy due to spurious features in the directional spectra. Whilst wave measurements are well correlated with buoy measurements over the whole area of HF radar coverage, there is a reduction in accuracy and an increase in variance in the measurements away from the centre of the region due to the impact of reduced signal-to-noise and increased antenna sidelobe levels. These effects introduce spurious contributions to the directional spectra (illustrated in Figs. 7(b) and 8) and, hence, noise in the mean directions.

EuroROSE WERA wave measurement statistics can be compared to those obtained in SCAWVEX (Wyatt et al., 1999). The overall picture confirms the SCAWVEX results; that is, the measurements decrease in accuracy in higher seas. However, the Fedje experiment provided much higher seas and more often. The most significant difference that resulted from this is that mean periods at Fedje were much lower than those measured by the buoy (6.5 s cf. $7.6 \mathrm{~s})$-this has previously been a parameter that has been measured with very little bias (SCAWVEX means of $5.4 \mathrm{~s}$ cf. 5.6 $\mathrm{s}$, respectively). The reason for this is that, firstly, the overestimation in high-frequency energy reported by Wyatt et al. (1999) in higher seas is more serious as Hs increases (a mean bias of $20 \%$ in the $0.2-0.3 \mathrm{~Hz}$ frequency range was reported during SCAWVEX compared to $37 \%$ in this range at Fedje). Also, because mean periods in the SCAWVEX experiments were much lower than those at either Fedje or Gijon (5.6 s compared to 7.6 and $8.1 \mathrm{~s}$, respectively). However, although these errors are associated with errors in the distribution of energy with frequency and direction (which are clear when full directional spectra are compared and from Figs. 3 and 4), they do not seem to have much impact on the statistics of significant wave height or mean direction. There is some variation in the mean bias of the WERA Hs measurements $(11 \%$ in SCAWVEX cf. $6 \%$ at Fedje and Gijon). The improvement during EuroROSE could be due to improvements to the radar hardware because the SCAWVEX experiment was the first full trial of the system. Mean direction differences are less than $2 \pm 28^{\circ}$ for both SCAWVEX and Fedje (no buoy comparisons available at Gijon; however, comparisons with WaMoS suggest WERA directions are noisier due to increased influence of sidelobe contamination at the WaMoS location). The variance would be reduced with better quality control procedures giving a robust, but perhaps less often available, mean direction measurement. The significant wave-height correlation coefficient is slightly reduced (0.93 cf. 0.96) and its variance slightly increased (19\% cf. 17\%) at Gijon compared to Fedje, reflecting a reduction in accuracy of the measurements away from the centre of the radar coverage region. This variation in accuracy with position has also been identified in a detailed comparison with the SWAN wave model (Caires, 2000).

\subsection{WaMoS performance}

WaMoS had a lower limit of about $2 \mathrm{~m}$ for successful operation at Fedje and $1.5 \mathrm{~m}$ at Gijon and an upper frequency limit of $0.15-0.2 \mathrm{~Hz}$. Differences at the different locations are explained by the antenna heights, radar power and rotation times. The influence of wind was particularly evident at Gijon, where WaMoS had a lower wind speed limit of about $3 \mathrm{~m} / \mathrm{s}$, thus missed some swell events. The other factors that have been identified as influencing the accuracy and availability of wave data are rain and wave breaking. At higher wave heights/wind speeds and lower frequencies, agreement with the buoy is generally good when differences in location are taken into account. Coastal effects, such as wave refraction, damping, shoaling and breaking, can lead to locally 
varying wave fields and make absolute comparisons between instruments difficult, especially if there is no spatial overlap in coverage as has been the case for the WaMoS and buoy comparisons in these experiments. Wave breaking does reduce the accuracy in significant wave-height measurement. WaMoS Hs measurements have a higher variance and lower correlation compared to the buoy than those of WERA although some of this may be explained by differences in location between WaMoS and buoy.

There have not been many publications in the past regarding quantitative validation of the WaMoS measurements. Borge et al. (1999a,b) presented some correlation coefficients for wave height. Hessner et al. (2001) present some more detailed statistics. Correlation coefficients at Fedje and Gijon are similar to those reported in the earlier work as are mean biases in Hs; however, the EuroROSE measurements show more scatter (20-30\% compared to about $15 \%)$. The higher figure is the comparison at Fedje, where the radar was farther from the buoy than was the case of the Torres radar at Gijon, suggesting again that differences in location are important. The variance in peak period is similar to earlier work although biases are slightly higher at $0.5-1 \mathrm{~s}$ rather than $<0.5 \mathrm{~s}$. The peak direction bias at Fedje (comparisons only include those cases that are least likely to be influenced by the sheltered location of the WaMoS) was $2^{\circ}$ exactly the same as reported earlier, but with a larger variability $\left(22^{\circ} \mathrm{cf} .10^{\circ}\right)$. Some wave refraction was observed for those cases where sheltering was expected to have an effect. Examples of wave reflection were also found in some conditions. The quality control measures introduced at Gijon produce more reliable measurements then were obtained at Fedje. The quantitative comparisons referred to here have excluded all Fedje measurements with wave heights $<2 \mathrm{~m}$ as a crude quality control measure.

\subsection{WAM performance}

The WAM model compared very well with the wave buoy, in general. There is evidence that it responds slowly to changing conditions perhaps due to the coarser resolution in wind forcing. Comparisons with WaMoS indicate that possible sheltering of waves from the north and the west of north is not well represented in the model perhaps due to an inadequate representation of coasts and islands.

As wave energy from the ocean, propagating through the assimilation area, in this case will reach shore shortly after the assimilation time, the impact of assimilation on the wave forecasts has been very limited. This can be seen from Table 5, which shows some statistics from a comparison between the significant wave height from the model at analysis time and 1-, 2-, 3-, 4-, 5- and 6-h prognosis, respectively, and the wave buoy. The significant wave heights

Table 5

Comparison of Hs from WAM and wave buoy

\begin{tabular}{lllllllll}
\hline $\begin{array}{l}\text { Prognosis } \\
\text { time }(\mathrm{h})\end{array}$ & $N$ & $\begin{array}{l}\text { Mean } \\
\text { Hsobs }\end{array}$ & $\begin{array}{l}\text { Mean } \\
\text { HsWAM }\end{array}$ & $\begin{array}{l}\text { St. dev. } \\
\text { diff. }\end{array}$ & RMS & $r$ & $\begin{array}{l}\text { St. dev. } \\
\text { Hsobs }\end{array}$ & $\begin{array}{l}\text { St. dev. } \\
\text { HsWAM }\end{array}$ \\
\hline 0 & 1074 & 2.85 & 3.05 & 0.55 & 0.58 & 0.937 & 1.56 & 1.42 \\
1 & 1075 & 2.85 & 2.87 & 0.55 & 0.55 & 0.937 & 1.56 & 1.41 \\
2 & 1076 & 2.85 & 2.86 & 0.55 & 0.55 & 0.937 & 1.56 & 1.41 \\
3 & 1077 & 2.85 & 2.86 & 0.55 & 0.55 & 0.937 & 1.56 & 1.41 \\
4 & 1078 & 2.85 & 2.86 & 0.55 & 0.55 & 0.935 & 1.56 & 1.42 \\
5 & 1079 & 2.85 & 2.86 & 0.56 & 0.56 & 0.934 & 1.56 & 1.56 \\
6 & 1080 & 2.85 & 2.86 & 0.56 & 0.56 & 0.932 & 1.44 \\
\hline
\end{tabular}

$N$-Number of entries.

Mean Hsobs-Mean observed significant wave height.

Mean HsWAM-Mean significant wave height from WAM.

St. dev. diff.-Standard deviation of the difference in Hs between observation and WAM.

RMS-Root-mean-square difference.

$r$-Correlation coefficient.

St. dev. Hsobs - Standard deviation of observed Hs.

St. dev. HsWAM-Standard deviation of Hs from WAM. 
from the model and the buoy are well correlated with a correlation coefficient between 0.932 and 0.937 . The RMS difference is between 0.55 and $0.58 \mathrm{~m}$. The mean significant wave height from the model analysis is $0.20 \mathrm{~m}$ higher than the mean of the significant wave height measured by the buoy. However, the bias is almost zero for the prognosis. This indicates that the assimilation of the HF radar data increases the significant wave height in the wave model. Nevertheless, the effect of the assimilation almost disappears in the model already $1 \mathrm{~h}$ after the analysis time. To get larger impact of data assimilation on the wave prognosis, it is necessary to have wave measurements over a wider area. The increase in Hs due to assimilation is not surprising because it is clear that the HF radar significant wave-height values are generally overestimated (see above).

\subsection{Buoy performance}

The Gijon experiment confirmed the main problem with buoy measurements. There were two directional buoys that were expected to contribute useful 'seatruth' for the radar measurements. One of these disappeared and the second failed to work. Whereas problems with the radars (e.g., replacing and repairing WERA antennas after a lightning strike) could be solved relatively easily because they were located on land, problems with buoys are often more difficult to resolve in a short time scale because they are offshore. When buoys work, as at Fedje, they do provide good quality data.

As both WERA and WaMoS measure the directional spectrum, for a full intercomparison with the buoy data, it is necessary to estimate buoy directional spectra, and, in this work, the maximum entropy method (Lygre and Krogstad, 1986) has been used. The validity of this method was explored in Krogstad et al. (1999) and the spectra measured at Fedje also suggest that the method does yield reasonable spectra comparable with those measured by WaMoS with perhaps slightly broader directional spreading. There are occasional cases when the tendency of the method to generate large peaks is evident, one such being the example shown in Fig. 8.

During the Fedje experiment, the maximum wave height measured by the buoy was nearly $12 \mathrm{~m}$ and was above $10 \mathrm{~m}$ for a few hours. Measurements of this order were also obtained with WERA at the same time; however, the quality of the data (as measured by signal-to-noise levels and signal shape) was not considered good enough for a valid measurement. WaMoS measured about $8 \mathrm{~m}$ at this time and a similar wave height was predicted by WAM. Measurements at offshore sites to the northwest and southwest of the buoy both record highest wave heights of $7.9 \mathrm{~m}$ during this storm which is more consistent with the local wind field. During the later storm in March 14 (see Fig. 3), when wind speeds were similar, the buoy and offshore measurements are closer. The main difference between these two events is the peak period which was near $16 \mathrm{~s}$ at the offshore location in March 6-7 compared with about $12 \mathrm{~s}$ in March 14. Although the buoy was in deep water $(200 \mathrm{~m})$, there are significant local topographic variations with a depth of only $18 \mathrm{~m}$ at $2 \mathrm{~km}$ to the east and $78 \mathrm{~m}$ at $1.5 \mathrm{~km}$ to the southeast. The scales of these variations are too small to be included on the map in Fig. 1. The waves are propagating from the northwest so it is not clear how these topographic variations could be influencing the local wave height. There is unfortunately no collocated or cotemporal satellite data in March 6-7 to shed further light on this mystery.

\subsection{Complementarity}

The added value obtained by integrating the wave measurements with the wave model was most obviously seen in the data display to users. WAM provided continuous spatial and temporal coverage and, therefore, compensated for the variation in spatial coverage and limitations in high sea states of WERA and the limitations in low sea states of WaMoS. The different strengths of the two instruments meant that real-time data was available to users at all times to provide confidence in the WAM nowcasts and predictions.

The major achievement of EuroROSE is the provision of the technology to integrate all the measurements and modelling components in real time in a manner that proved to be accessible for users.

\subsection{Recommendations}

WERA coverage and spatial resolution provides useful real-time monitoring data; however, especially 
for waves, the spatial scale is not sufficient to have a long-term impact on forecasts. Longer-range radar systems can extend the coverage to over $100 \mathrm{~km}$ (and also provide more accuracy in higher sea states). The possibility of nesting such longer-range systems with WERA providing higher resolution, shorter range near to the coast, WaMoS at the coast and satellites providing less frequent data in the open ocean, thus complementing nested modelling, should be explored.

More attention must be given to better quality control of the WERA wave measurements. It may be better to accept a reduction in the number of measurements (or at least in the full range of parameters) in order to increase the accuracy of those that are provided (as was done with WaMoS during the Gijon experiment). This applies particularly to directional parameters and to measurements away from the centre of the coverage region. Whilst improvements have been noted in significant wave-height accuracy and reliability, work is needed on the signal processing and inversion stages of the HF radar procedure to increase the reliability and accuracy of the shape of the directional spectra.

Schemes to assimilate directional wave parameters should be developed. These may improve the performance of the model near to the coast and in changing wind conditions.

The experiments have demonstrated that the qualitative and quantitative comparison of wave data taken in coastal areas requires a good knowledge of the local environment. Coastal effects, such as wave refraction, damping, shoaling and breaking, can lead to locally varying wave fields and make absolute comparisons between instruments difficult. In a future experiment, it would be useful to colocate WERA, WaMoS and a directional wave buoy for a more conclusive validation of the two radar systems.

\section{Acknowledgements}

This work has been partly funded by EU contract MAS3-CT98-0168. We are grateful to all the organisations involved in the field work in Norway, including the Norwegian Coast Directorate, and, in particular, the Fedje Vessel Traffic Service, the municipal governments of Fedje and Øygarden, the owners of land at Lyngøy, Fedje and Nordøy for their permission to set up the antennas; and, in Spain, including the Port of Gijon, Local Government of Gijon City and the Spanish Society for Maritime Safety and Rescue (SASEMAR).

\section{References}

Borge, J.C.N., Hessner, K., Reichert, K., 1999a. Estimation of the significant waveheight with X-band radar. Proceedings of OMAE99. ASME, New York.

Borge, J.C.N., Reichert, K., Dittmer, J., 1999b. Use of nautical radar as a wave monitoring instrument. Coastal Engineering 37, 331-342.

Breivik, L.A., Reistad, M., 1994. Assimilation of ERS-1 altimeter waveheights in an operational numerical wave model. Weather and Forecasting 9, 440-551.

Breivik, Ø., Saetra, Ø., 2001. Real time assimilation of HF radar currents into a coastal ocean model. Journal of Marine Systems $28,161-182$.

Caires, S., 2000. Comparative study of HF radar measurements and wave model hindcasts in shallow waters. $\mathrm{PhD}$ thesis, available from University of Sheffield Library, Sheffield, UK.

Essen, H.-H., Breivik, Ø., Günther, H., Gurgel, K.-W., Johannessen, J., Klein, H., Schlick, T., Stawarz, M., 2002. Coastal currents off the Atlantic coasts of Norway and Spain: measurements and models. The Global Atmosphere and Ocean Systems (submitted for publication).

Gurgel, K.-W., Antonischki, G., Essen, H.-H., Schlick, T., 1999. Wellen Radar (WERA): a new ground-wave HF radar for ocean remote sensing. Coastal Engineering 37, 219-234.

Hessner, K., Reichert, K., Dittmer, J., 2000. EuroROSE Experiment 1-Feb/Mar 2000, Hellisøy-Nordøy, June 2000.

Hessner, K., Reichert, K., Dittmer, J., 2000. EuroROSE Experiment 2-Oct/Nov 2000, Cabo Peñas-Cabo de Torres, May 2001.

Hessner, K., Reichert, K., Dittmer, J., Nieto-Borge, J.C., Günther, H., 2001. Evaluation of WaMoS II wave data. In: Edge, B.L., Hemsley, J.M. (Eds.), Ocean Wave Measurement and Analysis. Proceedings of WAVES2001, vol. 1, pp. 221-230.

Komen, G.J., Cavaleri, L., Donelan, M., Hasselmann, K., Hasselmann S., Janssen, P.A.E.M., 1994. Dynamics and Modelling of Ocean Waves. Cambridge Univ. Press, Cambridge.

Krogstad, H.E., Wolf, J., Thompson, S.P., Wyatt, L.R., 1999. Methods for the intercomparison of wave measurements. Coastal Engineering 37, 235-258.

Lygre, A., Krogstad, H.E., 1986. Maximum entropy estimation of the directional distribution in ocean wave spectra. Journal of Physical Oceanography 16, 2052-2060.

Sova, M.G., 1995. The sampling variability and the validation of high frequency wave measurements of the sea surface. PhD thesis (unpublished), available from University of Sheffield Library, Sheffield, UK.

WAMDI Group, 1988. The WAM Model-a third generation wave prediction model. Journal of Physical Oceanography $18,1775-1810$. 
Wyatt, L.R., 2000. Limits to the inversion of HF radar backscatter for ocean wave measurement. Journal of Atmospheric and Oceanic Technology 17, 1651-1666.

Wyatt, L.R., 2002. The interpretation and validation of measurements of the ocean wave directional spectrum. In: Anderson, C., Barnett, V., Chatwin, P., El-Shaarawi, A. (Eds.), Quantitative Methods for Current Environmental Issues. Springer-Verlag, London, pp. 113-128.

Wyatt, L.R., Green, J.J., 2001. The EuroROSE Project-Validation and Intercomparison of wave measurements and models at Fedje. SCEOS report, available from Department of Applied Mathematics, University of Sheffield, Sheffield, UK.
Wyatt, L.R., Thompson, S.P., Burton, R.R., 1999. Evaluation of HF radar wave measurement. Coastal Engineering 37, 259-282.

Wyatt, L.R., Green, J.J., Gurgel, K.-W., Nieto Borge, J.C., Reichert, K., Hessner, K., Gunther, H., Rosenthal, W., Saetra, O., Reistad, M., 2002. Comparisons of wave measurements from the EuroROSE Fedje experiment. Ocean wave measurement and analysis. In: Edge, B.L., Helmsley, J.M. (Eds.), Proceedings of WAVES2001, vol. 1. ASCE, New York, pp. 201-210. 